ARTICLE

\title{
Membrane potential shapes regulation of dopamine transporter trafficking at the plasma membrane
}

\author{
Ben D. Richardson ${ }^{1, \star}$, Kaustuv Saha ${ }^{1, \star}$, Danielle Krout ${ }^{2}$, Elizabeth Cabrera' ${ }^{1}$ Bruce Felts ${ }^{2}$, L. Keith Henry ${ }^{2}$,
} Jarod Swant', Mu-Fa Zou ${ }^{3}$, Amy Hauck Newman ${ }^{3}$ \& Habibeh Khoshbouei ${ }^{1}$

The dopaminergic system is essential for cognitive processes, including reward, attention and motor control. In addition to DA release and availability of synaptic DA receptors, timing and magnitude of DA neurotransmission depend on extracellular DA-level regulation by the dopamine transporter (DAT), the membrane expression and trafficking of which are highly dynamic. Data presented here from real-time TIRF (TIRFM) and confocal microscopy coupled with surface biotinylation and electrophysiology suggest that changes in the membrane potential alone, a universal yet dynamic cellular property, rapidly alter trafficking of DAT to and from the surface membrane. Broadly, these findings suggest that cell-surface DAT levels are sensitive to membrane potential changes, which can rapidly drive DAT internalization from and insertion into the cell membrane, thus having an impact on the capacity for DAT to regulate extracellular DA levels.

\footnotetext{
${ }^{1}$ Department of Neuroscience, Evelyn F. and William L. McKnight Brain Institute, University of Florida, Gainesville, Florida 32610, USA. ${ }^{2}$ Department of Basic Sciences, University of North Dakota School of Medicine and Health Sciences, Grand Forks, North Dakota 58203, USA. ${ }^{3}$ Medicinal Chemistry Section, Intramural Research Program, National Institute on Drug Abuse, Baltimore, Maryland 21224, USA. * These authors contributed equally to this work. Correspondence and requests for materials should be addressed to H.K. (email: habibeh@ufl.edu).
} 
C entral nervous system dopaminergic (DAergic) neurotransmission is essential in multiple neurological functions, including cognition, extrapyramidal motor control, the reward pathway and attention ${ }^{1-4}$. In addition to the timing of vesicular release of dopamine (DA) and the expression profiles of G-protein-coupled DA receptors ${ }^{5,6}$, one major regulator of DA signalling magnitude and timing is the DA transporter (DAT), which rapidly transports extracellular DA into the intracellular space for vesicular re-packaging or effluxes DA through reversal of DAT-mediated transport ${ }^{7,8}$. Commonly abused psychotropic drugs, amphetamine (AMPH), methamphetamine and cocaine achieve their effects either by inducing DA efflux through DAT and/or blocking DA uptake ${ }^{9-11}$.

The physiological function of DAT to remove DA is coupled to the translocation of one $\mathrm{Cl}^{-}$and two $\mathrm{Na}^{+}$ions ${ }^{8,12,13}$, and can even function in the absence of substrate, conducting an uncoupled, cocaine-sensitive, depolarizing current under physiological conditions ${ }^{13,14}$, which is increased in hyperpolarized states ${ }^{10}$. In addition to direct modulation of transport function, DAT density at the cell membrane, and therefore its functional capacity, is also dynamic. Regulated trafficking mechanisms control surface-membrane DAT levels under physiological conditions ${ }^{15,16}$ and in response to DAT substrates $^{15,16}$, thus having an impact on DA homeostasis. Cell signalling molecules involved in the regulation of DAT trafficking range from protein kinase $\mathrm{C}(\mathrm{PKC})^{17,18}$, mitogen-activated protein kinase $^{19}$ to Akt (ref. 20) among others ${ }^{15,16}$ and determine the presence of DAT in regulated or constitutive pools segregated to specific membrane microdomains ${ }^{21-23}$. Many DAT substrates also influence DAT trafficking ${ }^{15,24,25}$, including DA and AMPH, which decrease DAT surface density ${ }^{26-28}$, and cocaine, which increases DAT surface expression ${ }^{29}$.

Interestingly, AMPH's effects are twofold, as it causes DAT internalization ${ }^{26-28}$ and a DAT-dependent membrane depolarization ${ }^{13,14}$, which suggests an influence on DAT trafficking via a voltage-dependent mechanism in addition to DAT phosphorylation. Indeed, previous studies using striatal synaptosomes have revealed a reduction in DA uptake in depolarized (elevated $\mathrm{KCl}$ ) conditions ${ }^{30,31}$, while in vitro preparations have suggested elevated DAT function at hyperpolarized states ${ }^{13}$. However, it is not known whether these changes in functional capacity arise from changes in ionic driving forces, essential for DA transport, changes in DAT protein presence at the membrane or both. While changes in the cell membrane voltage state are only typically considered in terms of neurotransmitter release, action potential generation and timing or in the activity of voltage-sensitive transmembrane proteins, it is possible that changes in membrane potential (MP) alone may rapidly and reversibly affect DAT trafficking to and from the cell surface. Here we use confocal and total internal reflection fluorescence microscopy (TIRFM), biochemistry, electrophysiology and optogenetics to demonstrate the degree to which surfacemembrane DAT levels are shaped by and sensitive to MP changes.

\section{Results}

MP depolarization reduces membrane DAT levels. AMPHmediated activation of DAT induces a depolarizing DAT-mediated $\mathrm{Na}^{+}$current and simultaneously causes internalization of cell-surface-membrane DAT ${ }^{14,28}$. To determine whether AMPHinduced DAT internalization was the result of a psychostimulantspecific action or may be, in part, due to activation of voltagesensitive mechanisms, we performed live cell TIRFM of yellow fluorescent protein-tagged DAT (YPF-DAT) in Human Embryonic Kidney (HEK) cells when perfused with only extracellular solution (vehicle), $10 \mu \mathrm{M}$ AMPH or $100 \mathrm{mM} \mathrm{KCl}$ (Fig. 1), which depolarized cells by 13.5 and $35.7 \mathrm{mV}$, respectively (Fig. 1e). The distribution of YFP (yellow fluorescent protein)DAT at the cell membrane (TIRFM footprint) was unchanged throughout perfusion of vehicle, whereas $10 \mu \mathrm{M} A M P H$ noticeably altered the YFP signal in the TIRFM footprint within the first $60 \mathrm{~s}$, causing a reduction in surface-membrane high-intensity regions and puncta that did not recover in washout (Fig. 1a,b and Supplementary Fig. 1a), in line with previous reports at longer AMPH treatment durations ${ }^{32}$. Similarly, depolarizing 100-mM KCl-based external solution significantly altered the YFP-DAT distribution in TIRFM footprint; however, the effects occurred rapidly, obvious within $30 \mathrm{~s}$, and typically all YFP puncta and high-intensity regions were absent from the surface membrane after 3 min (Fig. la,b,d). In contrast to AMPH, treatment with $\mathrm{KCl}$ resulted in the return of YFP signal profile and the reappearance of YFP puncta immediately on washout (Fig. 1a and Supplementary Movie 1). To determine the relative specificity of this effect of depolarization for DAT, we identically depolarized HEK cells transfected with an eYFP-tagged version of an unrelated naturally occurring membrane protein, GPR40 (ref. 33), which had a membrane distribution similar to DAT, but its trafficking appeared insensitive to depolarization (Supplementary Fig. 1b,c).

Since the depolarization induced by $\mathrm{KCl}$ will likely increase free $\left[\mathrm{Ca}^{2+}\right]$ and trigger the activation of $\mathrm{Ca}^{2+}$-dependent signalling molecules, we chose to determine the role of CaMKII and PKC in initiating this depolarization-induced redistribution. The depolarization-induced loss of YFP-DAT signal did not appear affected by the PKC inhibitor, bisindolylmaleimide I $(10 \mu \mathrm{M}$; Supplementary Fig. 2). However, the $\mathrm{KCl}$ depolarization-induced loss of YFP-DAT surface puncta was significantly reduced in the presence of the CaMK inhibitor KN93 $(10 \mu \mathrm{M})$ relative to the same treatment in the presence of the inactive homologue, KN92 $(10 \mu \mathrm{M}$; Fig. 1c,d), which produced results similar to $\mathrm{KCl}$ treatment alone (Fig. 1a-d). However, because of the KN93induced attenuation of the depolarization-triggered $\mathrm{Ca}^{2+}$ influx (Supplementary Fig. 3), we chose to biochemically inhibit CaMKII $\alpha$ specifically and assess membrane DAT using TIRFM by co-expressing a kinase-inactive version of CaMKII $\alpha$, a green fluorescent protein (GFP)-tagged K42R mutant and RFP (red fluorescent protein)-DAT. In response to $\mathrm{KCl}$-induced depolarization, RFP-DAT alone behaved similarly to YFP-DAT; however, when GFP-CaMKII $\alpha(\mathrm{K} 42 \mathrm{R})$ was co-expressed, $\mathrm{KCl}$ treatment was unable to alter the membrane distribution of RFP-DAT (Fig. 1c,d). These changes in membrane DAT in response to depolarization $(100 \mathrm{mM} \mathrm{KCl}$ application) and repolarization (washout) suggest that the MP state is capable of bidirectionally shaping the cell-surface distribution of DAT through activation of CaMKII $\alpha$.

Membrane DAT reduction is CaMKII $\alpha$ and dynamin dependent. To determine the degree to which real-time changes in the YFPDAT TIRFM footprint were indicative of changes in DAT protein density at the cell membrane, a cell-surface biotinylation assay was used to quantify differences in membrane DAT protein levels. In YFP-DAT HEK cells, compared with vehicle treatment $(100 \%, n=17)$, surface DAT (Fig. 2; see Supplementary Fig. 4 for antibody validation and total protein blots) was significantly reduced following a similar 5-min treatment as above with both $50 \mathrm{mM}(62 \pm 6 \%, n=14)$ and $100 \mathrm{mM}(70 \pm 5 \%, n=17) \mathrm{KCl}-$ based external solution as well as the positive control treatments with $\mathrm{AMPH}(10 \mu \mathrm{M} ; 59 \pm 7 \%, n=13)$ and the PKC agonist phorbol myristate acetate (PMA, $2.5 \mu \mathrm{M} ; 53 \pm 5 \%, n=13$ ). The CaMKII $\alpha$ dependency of this effect observed in TIRFM studies 
was also supported by biotinylation experiments (Fig. 2), wherein $100 \mathrm{mM} \mathrm{KCl}$ had little effect on membrane DAT protein when YFP-DAT HEK cells were transfected with the kinase-inactive, dominant-negative GFP-CaMKII $\alpha(\mathrm{K} 42 \mathrm{R})(105 \pm 11 \%, n=6)$ or in the presence of the CaMK inhibitor KN93 $(10 \mu \mathrm{M}$; $98 \pm 9 \%$, $n=9$ ), whereas the inactive homologue KN92 did not significantly block the $\mathrm{KCl}$-dependent reduction in surface DAT $(10 \mu \mathrm{M} ; 63 \pm 6 \%, n=12)$. To determine whether the reduction in membrane DAT distribution observed using TIRFM and confirmed using biotinylation was a trafficking event, we evaluated the capacity for depolarization to induce a loss in surface DAT in the presence of Dynasore, a dynamin inhibitor ${ }^{34}$. Indeed, inhibition of dynamin by Dynasore blocked depolarization$(115 \pm 6 \%, n=6)$, AMPH- $(101 \pm 11 \%, n=6)$ and PMAdependent $(108 \pm 8 \%, n=6)$ internalization of DAT in HEK cells, whereas expression of $\mathrm{CaMKII} \alpha(\mathrm{K} 42 \mathrm{R})$ only blocked depolarization- and PMA-dependent $(117 \pm 13 \%, n=6)$ but not AMPH-dependent $(66 \pm 9 \%, n=6)$ internalization (Fig. 2). Importantly, treatment with $100 \mathrm{mM} \mathrm{KCl}$ did not alter surface levels of the native or overexpressed, membrane-resident transferrin receptor in comparison with vehicle control, providing further support for the specificity of depolarizationinduced downregulation of membrane DAT (Supplementary Fig. 5). Taken together, these data suggest that CaMKII $\alpha$ - and dynamin-dependent pathways are involved in depolarizationdependent DAT trafficking at the cell membrane.

MP depolarization internalizes JHC 1-064/DAT complexes. Next, we used JHC 1-064 (ref. 35), a fluorescent cocaine analogue, to label cell membrane-resident DAT in HEK FLAG-DAT cells in conjunction with live cell confocal microscopy to investigate whether $\mathrm{KCl}$-induced membrane depolarization would drive the internalization of cell-surface JHC 1-064/DAT complexes, an approach used previously to study DAT trafficking to defined endosome compartments in vitro (Fig. $3 \mathrm{a})^{36}$. In all cases, the presence of JHC 1-064/DAT complex puncta in the intracellular space was limited or nonexistent at $4{ }^{\circ} \mathrm{C}$ (Fig. 3b). However, when changing bath temperature from 4 to $37^{\circ} \mathrm{C}$ with either vehicle or depolarizing (iso-osmotic) $100-\mathrm{mM} \mathrm{KCl}$-based external solution (Fig. 3b-d), the number of fluorescent punctate JHC 1-064/DAT complexes (Fig. 3c) and average intracellular fluorescence a
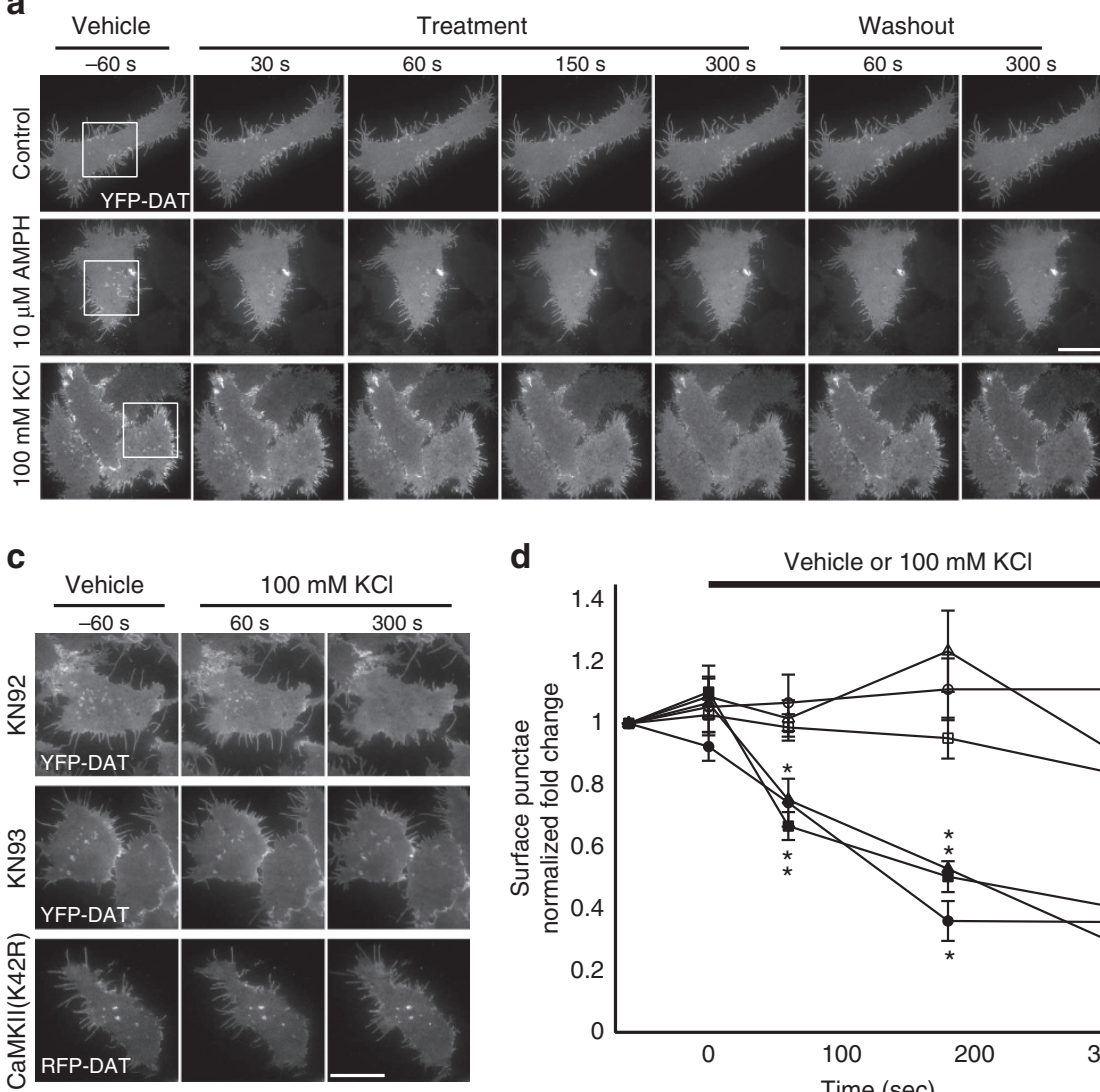

d

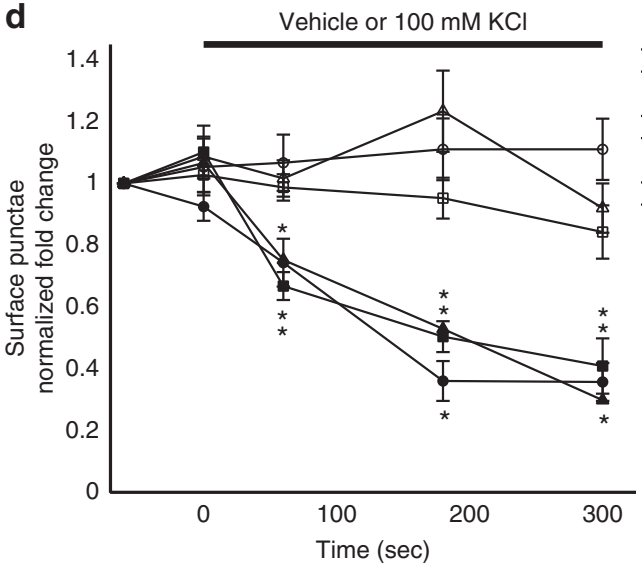

b

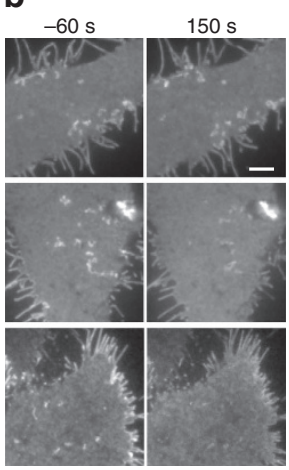

- YFP-DAT Vehicle $\rightarrow$ YFP-DAT KCl

$\triangle$ YFP-DAT+KN93 KCl — YFP-DAT+KN92 KCl ๑ RFP-DAT+CaMKII(K42R) KCl $\rightarrow$ RFP-DAT KCl

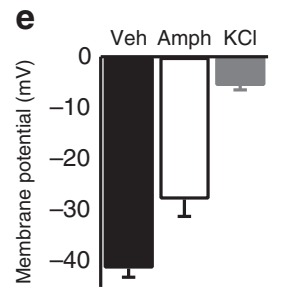

Figure 1 | Depolarization causes CaMK-dependent reduction of membrane YFP-DAT levels in HEK cells. (a) Representative live cell sequential TIRF microscopy images of YFP-DAT HEK cells $60 \mathrm{~s}$ before and throughout 5 -min perfusion with vehicle (standard external solution, top row), $10 \mu \mathrm{M}$ amphetamine (middle row; $N=5, n=14$ ) or depolarizing $100 \mathrm{mM} \mathrm{KCl-based} \mathrm{external} \mathrm{solution} \mathrm{(bottom} \mathrm{row)} \mathrm{followed} \mathrm{by} \mathrm{a} \mathrm{5-min} \mathrm{washout} \mathrm{period.} \mathrm{Scale} \mathrm{bar,}$ $20 \mu \mathrm{m}$. (b) Enlarged insets corresponding to boxes in left-most column before and $150 \mathrm{~s}$ after vehicle (top pair), $100 \mathrm{mM} \mathrm{KCl}$ (middle pair) and $10 \mu \mathrm{M}$ amphetamine (bottom pair). Scale bar, $5 \mu \mathrm{m}$. (c) TIRF microscopy images of YFP-DAT HEK cells $60 \mathrm{~s}$ before and throughout 5-min perfusion, with $100 \mathrm{mM}$ $\mathrm{KCl}$ pre-incubated with $10 \mu \mathrm{M} \mathrm{KN92} \mathrm{(top),} 10 \mu \mathrm{M} \mathrm{KN93} \mathrm{(middle)} \mathrm{or} \mathrm{expressing} \mathrm{a} \mathrm{kinase-inactive} \mathrm{CaMKII(K42R).} \mathrm{Scale} \mathrm{bar,} 20 \mu \mathrm{m}$. (d) Mean \pm s.e.m. Normalized fold change in number of YFP-DAT puncta per cell when perfused with vehicle (open circles; $N=5$ experiments, $n=17$ cells), $100 \mathrm{KCl}$ only (closed circles; $N=6, n=14$ ), $100 \mathrm{mM} \mathrm{KCl}$ when pre-incubated and perfused with $10 \mu \mathrm{M} \mathrm{KN92} \mathrm{(closed} \mathrm{triangles;} N=5, n=12$ ) or $10 \mu \mathrm{M}$ KN93 (open triangles; $N=6, n=23$ ) and RFP-DAT puncta expressed alone (closed squares; $N=9, n=9$ ) or co-expressing a kinase-inactive GFP-CaMKII(K42R) (open squares; $N=10, n=12$ ) during $100 \mathrm{mM} \mathrm{KCl}$ perfusion. (e) Mean \pm s.e.m. Steady-state membrane potential of YFP-DAT HEK cells perfused with vehicle, $10 \mu \mathrm{M}$ amphetamine or $100 \mathrm{mM} \mathrm{KCl}\left(n=5-7\right.$ cells per group). Using independent samples $t$-test ${ }^{\star} P<0.05$ for comparison of $100 \mathrm{mM} \mathrm{KCl}$ effects with respective controls. 


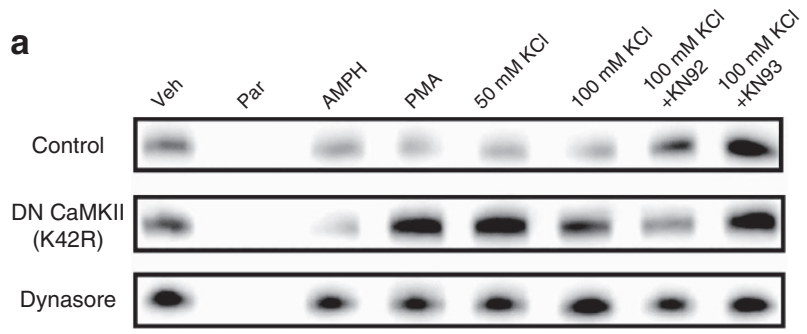

b

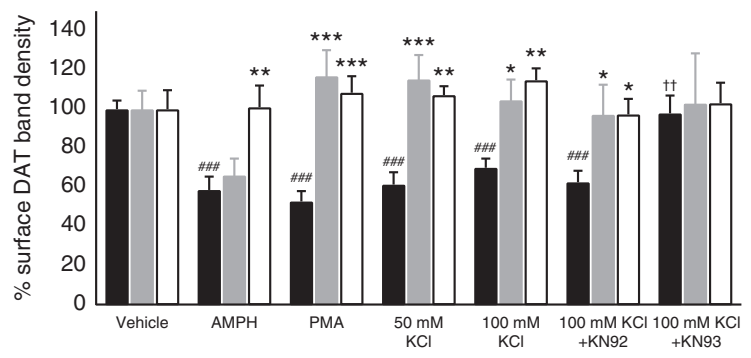

Figure 2 | Depolarization-induced reduction in surface-membranebiotinylated DAT is due to CaMKII-dependent endocytosis.

(a) Representative western blots show the surface DAT present under each indicated condition. (b) Mean \pm s.e.m. DAT band density from YFP-DAT HEK cells (control, black bars) or YFP-DAT HEK cells transfected with GFP-C1-CAMKII $\alpha-K 42 R$ (grey bars) or YFP-DAT HEK pre-treated (30 min) with external solution (vehicle) or $80 \mu \mathrm{M}$ Dynasore (white bars), followed by 30-min treatment with vehicle, vehicle $+10 \mu \mathrm{M}$ KN92 or vehicle $+10 \mu \mathrm{M} \mathrm{KN93.} \mathrm{Cells} \mathrm{normalized} \mathrm{to} \mathrm{vehicle} \mathrm{treatment}$ from at least five independent experiments indicate that $\mathrm{AMPH}$,

PMA and depolarization-induced reduction in surface DAT are endocytosis-dependent (Dynasore-sensitive), and both PMA- and depolarization-induced internalization are CaMKII $\alpha$-dependent. Depolarization-induced internalization is sensitive to both pharmacological and molecular inhibition of CaMKII activity. A two-way analysis of variance (ANOVA) with Bonferroni post hoc test was performed to identify significant differences from control $\left({ }^{\star} P \leq 0.05 ;{ }^{\star \star} P \leq 0.01 ;{ }^{\star \star \star} P \leq 0.001\right)$, a one-way ANOVA with a Dunnett's post hoc test to determine changes

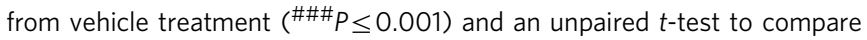
KN92 and KN93 treatments ( $\left.{ }^{\dagger \dagger} P \leq 0.01\right)$. See text for number of experiments. intensity (Fig. 3d) were significantly greater in depolarizing $\mathrm{KCl}$ based external solution $(3.2 \pm 0.3$ puncta per cell; normalized fold change in intracellular JHC 1-064 intensity: $0.26 \pm 0.05$ ) compared with vehicle $(1.7 \pm 0.2$ puncta per cell; normalized fold change in intracellular JHC 1-064 intensity: $-0.10 \pm 0.05$ ).

MP depolarization redistributes DAT into early endosomes. To determine the identity of the intracellular destination of depolarization-dependent internalized DAT, fluorescent versions of the endosome markers (which were not apparent at the cell membrane in TIRFM; see Supplementary Fig. 6), EEA1 (TagRFPT-EEA1) that marks early endosomes or the recycling endosome marker Rab11 (DsRed-Rab11), were expressed in HEK YFP-DAT cells and then treated with standard external solution (vehicle), iso-osmotic $100-\mathrm{mM} \mathrm{KCl}$-based external solution for $5 \mathrm{~min}$ or $10 \mu \mathrm{M}$ AMPH for $5 \mathrm{~min}$ as a temporal comparison. Another time point of $60 \mathrm{~min}$ AMPH $(10 \mu \mathrm{M})$ treatment was used as a positive control as it has been shown previously to cause DAT internalization to specific endosomes ${ }^{18,37-39}$, and would thus allow for comparability to previous work. Average Pearson correlation coefficients per cell for intracellular YFP-DAT and TagRFP-TEEA1 or DsRed-Rab11 in vehicle (EEA1: $0.17 \pm 0.01$; Rab11: $0.19 \pm 0.01)$ were significantly less than in cells treated with AMPH at $5 \mathrm{~min}$ for EEA1 $(0.32 \pm 0.03$; Fig. $4 \mathrm{a}, \mathrm{b})$ and Rab11 (0.47 \pm 0.06 ; Fig. $4 \mathrm{c}, \mathrm{d})$, while 60-min AMPH treatment increased YFP-DAT association with EEA1 $(0.24 \pm 0.01$; Fig. $4 \mathrm{a}, \mathrm{b})$, but not Rab11 (0.22 \pm 0.15 ; Fig. 4c,d). Similarly, depolarizing conditions significantly enhanced the co-localization of intracellular YFPDAT with EEA1 (0.30 \pm 0.02 ; Fig. $4 \mathrm{a}$,b) over vehicle and 60 -min AMPH treatments, although comparable to the 5-min AMPH treatment. The treatment had no effect on the degree of association of intracellular YFP-DAT with Rab11 $(0.16 \pm 0.07$; Fig. 4c,d) compared with vehicle. While biotinylation and confocal imaging inherently lack the temporal resolution of TIRFM, the collective results indicate that MP depolarization rapidly reduces cell-surface-membrane DAT and internalizes the transporter to intracellular early endosome compartments, suggesting that membrane DAT levels and DAT trafficking may be partially dependent on the MP state and therefore could change rapidly with MP fluctuation on local changes in the activity of receptors, ion transporters and channels.
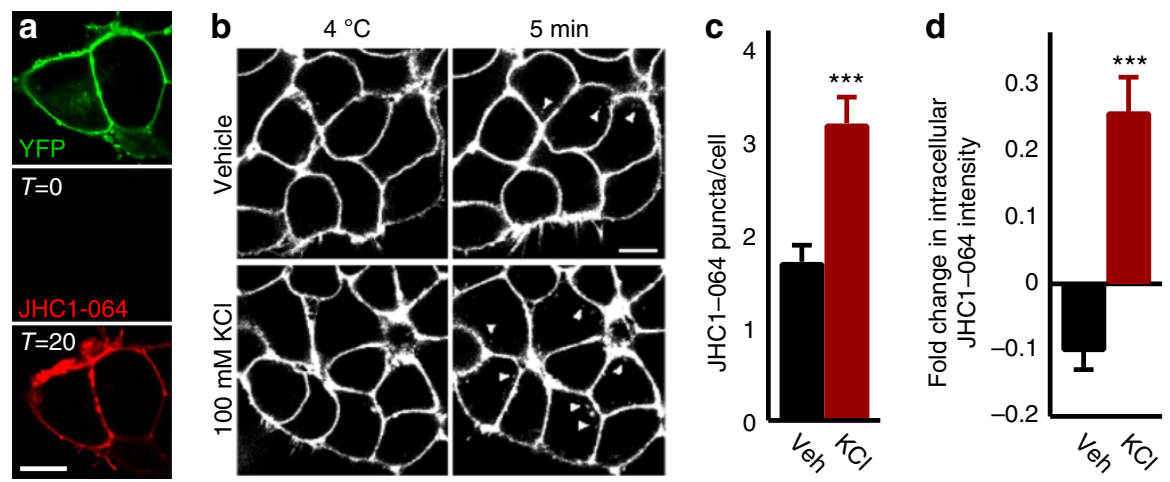

Figure 3 | Membrane depolarization with KCl increases internalization of JHC 1-064/DAT complexes in HEK cells. (a) JHC 1-064 binds to surface DAT in HEK cells. Confocal image of YFP signal in YFP-DAT HEK cells (top), with no initial detectable fluorescence emitted between 553 and $617 \mathrm{~nm}$ when excited with $561 \mathrm{~nm}$ (bottom left, $\mathrm{T}=0 \mathrm{~min}$ ) until after 20-min exposure to 10-nM JHC 1-064 (bottom right) corresponding with YFP fluorescence. (b) Representative confocal images of $\mathrm{JHC} 1-064 / \mathrm{DAT}$ labelling (white) at $\sim 4{ }^{\circ} \mathrm{C}$ and 5 min following solution change at $37^{\circ} \mathrm{C}$. Note the increase at 5 min in the number of white intracellular puncta in the $\mathrm{KCl}$ condition. (c,d) Mean \pm s.e.m. number of individual JHC 1-064/DAT puncta per cell (c) and normalized (to $4^{\circ} \mathrm{C}$ ) fluorescence intensity (d) in the intracellular space corresponding to vehicle $(N=3$ experiments, $n=69$ cells, black bars) or 100 mM $\mathrm{KCl}$-containing solution treatment $(\mathrm{N}=3$ experiments, $n=85$ cells, red bars). Independent samples $t$-tests were used to compare vehicle with $\mathrm{KCl}$ effects. Scale bars, $10 \mu \mathrm{m} .{ }^{\star \star \star} P<0.0001$ using independent samples $t$-test. 
a

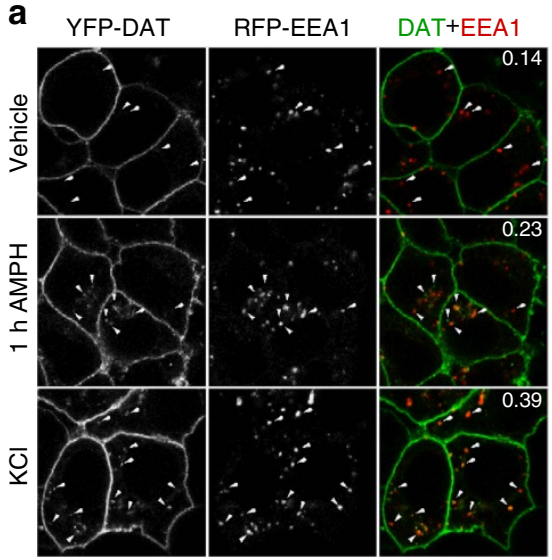

b

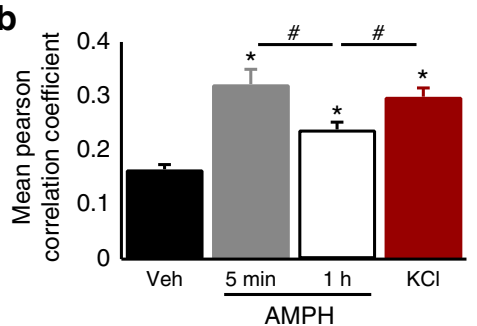

c

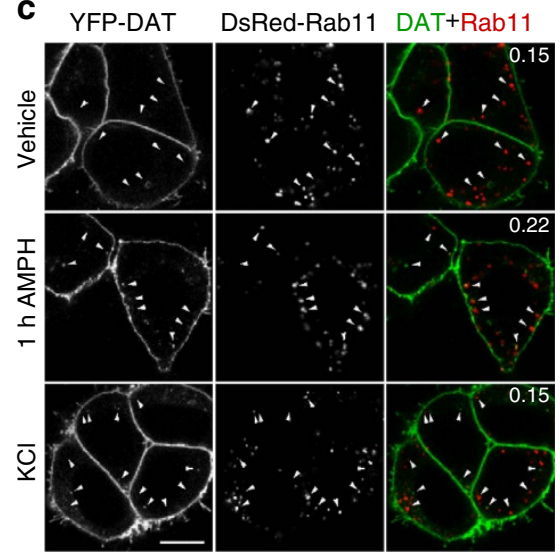

d

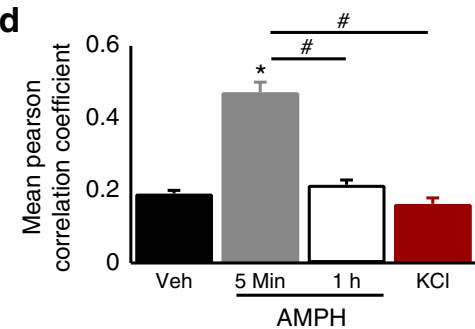

Figure 4 | Depolarization-dependent internalized DAT preferentially localizes to early but not recycling endosomes. (a,c) Representative single-plane confocal images of (left) YFP-DAT, (middle) TagRFP-T-EEA1 (a) or DsRed-Rab11 (c) and merge of the two (right) expressed in HEK cells treated with vehicle (top; EEA1: $N=5, n=106$; Rab11: $N=6, n=77$ ), $10 \mu \mathrm{M}$ amphetamine for $1 \mathrm{~h}$ (middle; EEA1: $N=3, n=50$; Rab11: $N=3, n=61$ ) or 5 min (EEA1: $N=2, n=27$; Rab11: $N=2, n=13$ ) or $100 \mathrm{mM} \mathrm{KCl}$ for 5 min (bottom; EEA1: $N=3, n=84 ;$ Rab11: $N=3, n=4$ ). (b,d) Mean \pm s.e.m. Pearson correlation coefficient per cell of intracellular YFP-DAT signal with EEA1 (b) or Rab11 (d) for vehicle, 5 min and $1 \mathrm{~h}$ amphetamine and $100 \mathrm{mM}$ KCl-treated cells. Value inset in merged images is the mean Pearsons correlation coefficient for cells in given image. Scale bar, $10 \mu \mathrm{m}$ and applies to all images. ${ }^{\star} P<0.05$ compared with vehicle, $\# P<0.05$ for indicated comparison using ANOVA with Bonferroni post hoc test.

Change in MP state alters cell surface membrane DAT levels. To further examine whether the membrane distribution of DAT is altered in response to MP changes (depolarization and hyperpolarization), we employed simultaneous single-cell TIRFM and whole-cell patch clamp electrophysiology (Fig. 5a). This technique allowed for time-resolved, bidirectional and precise control of the MP and provided internal controls in adjacent nonclamped cells. Acquisition of TIRFM image sequences (5-s intervals) throughout the course of 5-min duration voltage steps indicated that the surface YFP-DAT signal is stable during wholecell voltage clamp at $-40 \mathrm{mV}$ (typical MP for YFP-DAT HEK cells; Fig. 5b-e), but MP changes from baseline to hyperpolarized $(-60 \mathrm{mV}$; Fig. $5 \mathrm{~b}, \mathrm{f}-\mathrm{h})$ or depolarized $(+20 \mathrm{mV}$; Fig. $5 \mathrm{~b}, \mathrm{i}-\mathrm{k})$ potentials could rapidly (between frames, $5 \mathrm{~s}$ duration) increase or reduce, respectively, YFP-DAT puncta in the TIRFM footprint (Fig. 5b). In some cases, the 5-s interframe interval during depolarization was sufficient to eliminate all DAT puncta from the cell surface, and hyperpolarization to $-60 \mathrm{mV}$ caused complete recovery of the fluorescent signal profile within 5-10 s (Fig. 5b). The effect of the hyperpolarizing voltage step on the TIRFM footprint intensity of patch-clamped cells rapidly increased, typically plateauing within $5 \mathrm{~min}$, and began to reverse (decrease in intensity) following return of the membrane voltage to $-40 \mathrm{mV}$ (Fig. 5f). Continuous clamping of the MP at $-40 \mathrm{mV}$ did not significantly alter the YFP-DAT TIRFM footprint intensity at $3 \mathrm{~min}$ relative to adjacent cells ( $n=4$ clamped, four adjacent cells; $P>0.05$; Fig. $5 \mathrm{c}-\mathrm{e})$. However, when comparing intensity changes between clamped and adjacent cells $3 \mathrm{~min}$ into the voltage step, stepping the MP to $-60 \mathrm{mV}$ significantly increased the YFP-DAT TIRFM footprint intensity $(n=5$ clamped, five adjacent cells; $P<0.01$; Fig. $5 \mathrm{f}-\mathrm{h}$ ), while stepping to $+20 \mathrm{mV}$ produced the opposite effect $(n=5$ clamped, five adjacent cells; $P<0.01$; Fig. 5i-k). Further comparison of voltage effects between only cells clamped at -40 , -60 or $+20 \mathrm{mV}$ also indicates a significant difference in normalized YFP-DAT TIRFM footprint intensity for the $-60 \mathrm{mV}$ $(n=5$ cells; $P<0.05)$ and $+20 \mathrm{mV}(n=5$ cells; $P<0.001)$ condition when compared with the $-40 \mathrm{mV}$ ( $n=4$ cells) condition 5 min following the voltage change (Fig. 5l).

Change in MP state alters DAT-mediated current. Since the mere presence of DAT at the cell surface (YFP fluorescence signal) is not necessarily indicative of relative DAT function, we sought to determine whether MP change-induced variations in the surface DAT density (Fig. 5) correlated with the uncoupled DAT-mediated current. To investigate this, as in previous TIRFM experiments, the MP was clamped for $5 \mathrm{~min}$ at $+20,-40$ or $-60 \mathrm{mV}$ but was followed by acquisition of a baseline IV curve (Fig. 6a). The subsequent GBR12935-sensitive current was then taken as the DAT-mediated current for each cell for a given condition. Cells clamped at $-40 \mathrm{mV}$ (near their endogenous resting MP) had a DAT-mediated current amplitude of $-15.3 \pm 2.16 \mathrm{pA}$ ( $n=8$; Fig. $6 \mathrm{c}-\mathrm{f}$, black). However, when cells were depolarized to $+20 \mathrm{mV}$ for $5 \mathrm{~min}$ (Fig. $6 \mathrm{c}-\mathrm{f}$, red), the DAT-mediated current $(-8.8 \pm 1.6 \mathrm{pA}, n=7)$ was significantly reduced by $42.3 \%(P<0.05)$, and cells hyperpolarized to $-60 \mathrm{mV}$ for $5 \mathrm{~min}$ (Fig. $6 \mathrm{c}-\mathrm{f}$, blue) displayed a $47.7 \%$ larger $(P<0.05)$ DAT-mediated current $(-22.6 \pm 2.0 \mathrm{pA}, n=5)$ compared with cells held at $-40 \mathrm{mV}$. For comparison of MP state-dependent changes in YFP-DAT membrane density (Fig. 5) and DAT functional capacity, the average fold change in YFP-DAT TIRFM 
a

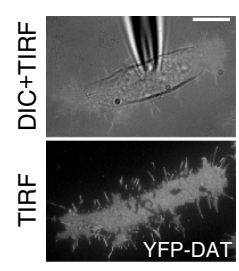

b

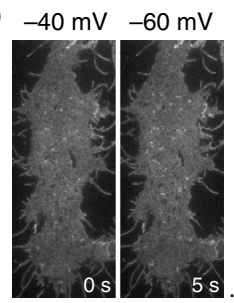

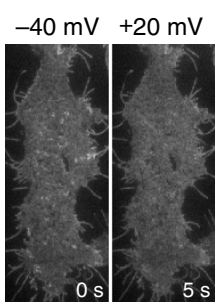

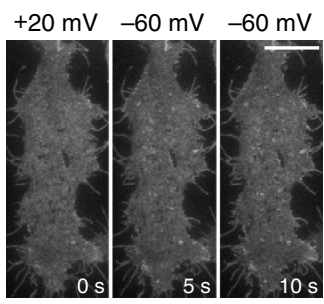

C

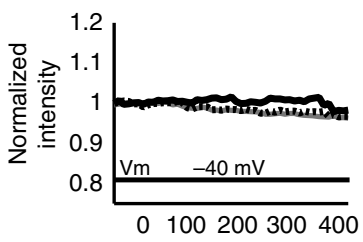

d

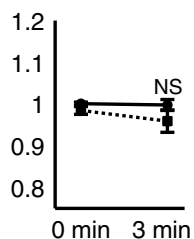

e 0 min
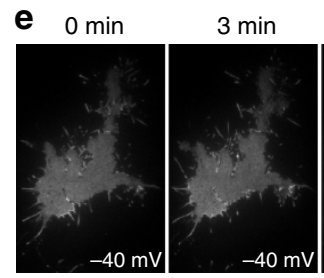

$5 \min$

$1 \mathrm{~min}$

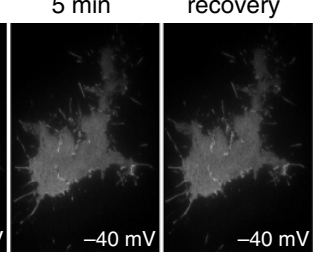

h
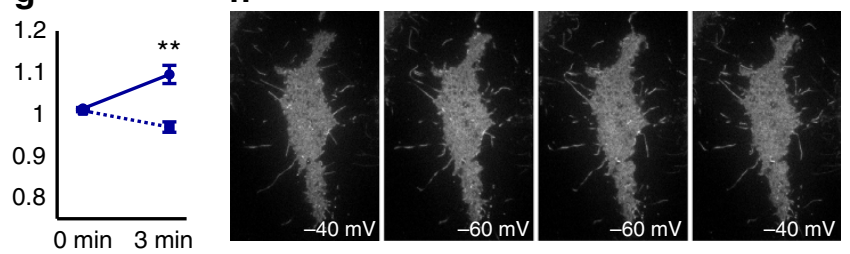

$\mathbf{k}$
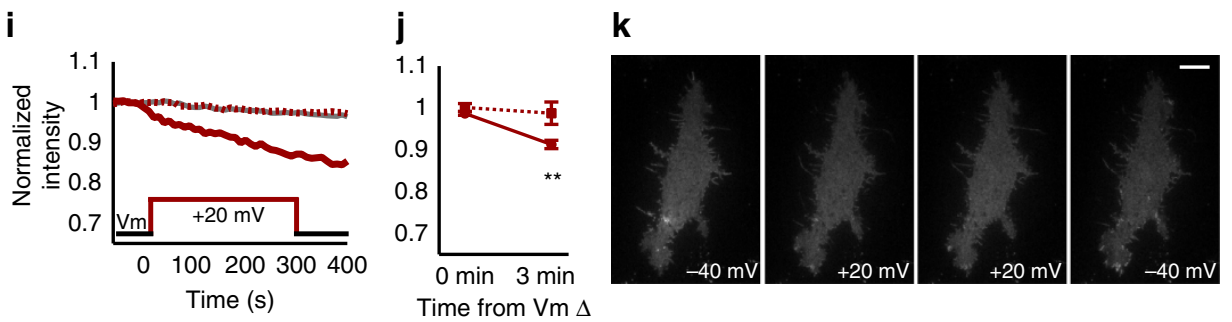
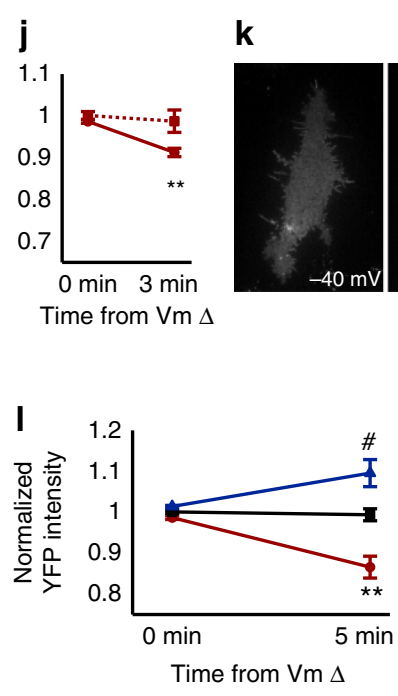

Figure 5 | Membrane potential state alters cell membrane YFP-DAT levels. (a) Simultaneous whole-cell patch-clamp recording with the patch pipette visible in dissolved inorganic carbon (top) of YFP-DAT HEK cell and TIRF imaging of YFP-DAT (white) of the same cell (bottom). (b) TIRF image sequence with 5-s interframe interval of YFP-DAT HEK cell footprint with the membrane potential clamped at indicated holding potentials. Hyperpolarized potentials ( -40 to $-60 \mathrm{mV}$ transition) increase cell-surface YFP-DAT signal, while depolarized potentials $(-40$ to $+20 \mathrm{mV}$ transition) reduces cell-surface YFP-DAT within $5 \mathrm{~s}$ and recovers within $5-10 \mathrm{~s}$ on hyperpolarization ( +20 to $-60 \mathrm{mV}$ transition). (c,f,i) The mean normalized intensity of the surface-membrane YFP-DAT over time for all clamped cells (solid line) held at $-40 \mathrm{mV}$ (c), $-60 \mathrm{mV}$ (f) and $+20 \mathrm{mV}$ (i) for $5 \mathrm{~min}$. Error bars are omitted for clarity, and the mean intensity for matched corresponding adjacent non-patched cells (colour-matched dashed line) and the mean of all non-patched adjacent cells (grey line) are included for comparison. (d, g,j) Normalized fluorescence intensity values for patched-clamped (solid line) and paired adjacent cells (dotted line) before ( $0 \mathrm{~min}$ ) and $3 \mathrm{~min}$ after membrane potential change ( $n=4-5$ cells per group). (e,h,k) Representative images of YFP-DAT HEK TIRFM footprints of patched cells before $(0 \mathrm{~min}), 3$ and $5 \mathrm{~min}$ after the membrane potential change and $1 \mathrm{~min}$ after returning the membrane potential to $-40 \mathrm{mV}$. (I) Average normalized YFP intensities at $5 \mathrm{~min}$ after the potential change to hyperpolarized ( $-60 \mathrm{mV}$, blue) or depolarized ( $+20 \mathrm{mV}$, red) membrane potentials are significantly different relative to continuous clamping near the endogenous ( $-40 \mathrm{mV}$, black) membrane potential. $\# P<0.05$, ${ }^{\star \star} P<0.001$ using independent samples $t$-test. All values are mean \pm s.e.m. Scale bars, $10 \mu \mathrm{m}$.

footprint intensity and DAT-mediated current amplitude for each MP-holding potential state are plotted against each other (Fig. 6f), indicating a positive correlation between the two measures. While the cell-surface-membrane DAT levels (TIRFM) are influenced by the MP state, these data imply that functional DAT may be particularly influenced by MP state changes as they are more profoundly affected.

Neuronal MP changes alter surface-membrane DAT levels. To determine whether MP influences surface-membrane DAT 
a

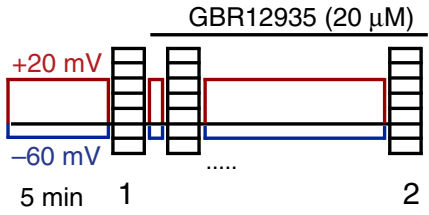

b

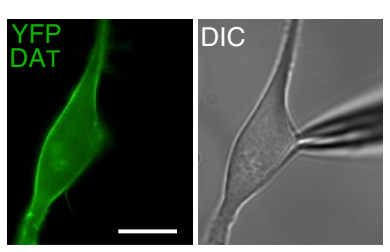

C

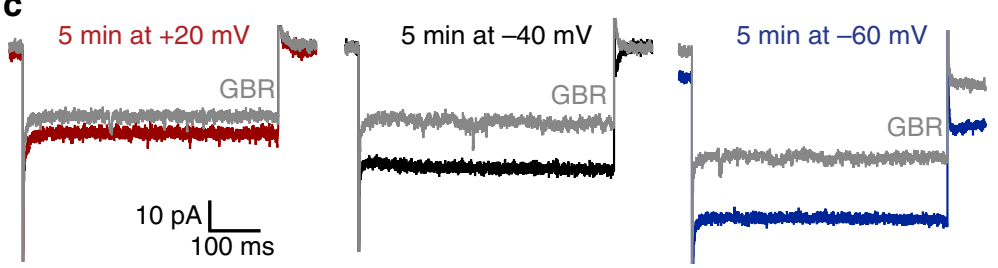

d
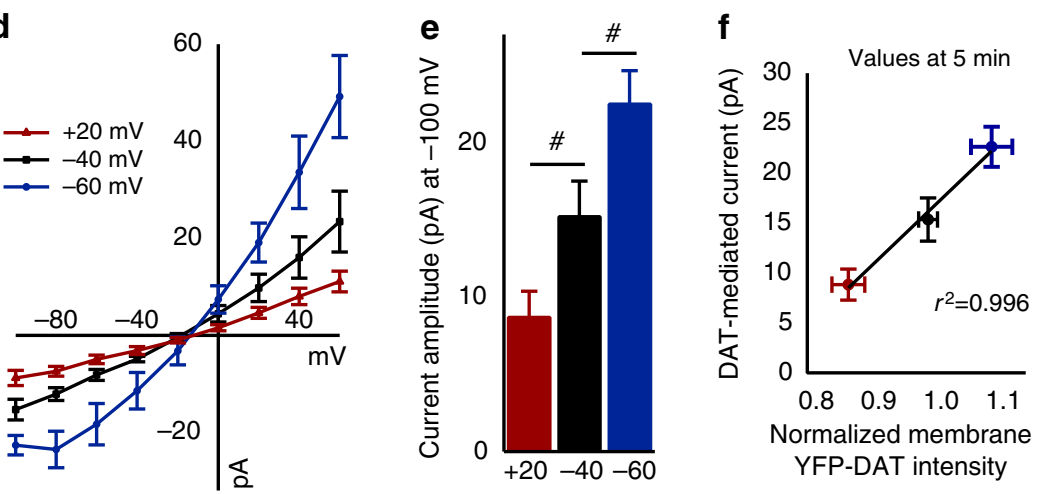

Figure 6 | Membrane potential state significantly alters DAT-mediated current. (a) Schematic of the whole-cell voltage protocol for examining membrane potential state-dependent changes in DAT-mediated current recorded from HEK cells expressing YFP-DAT (see Methods). (b) Representative image of an YFP-DAT HEK cell following the complete recording paradigm for the $+20-m V$ condition. Scale bar, $10 \mu m$. (c) Representative current responses of the $-100-\mathrm{mV}$ voltage step before (coloured trace) and after 20- $\mu \mathrm{M}$ GBR12935 (grey trace) for the given prolonged holding potential

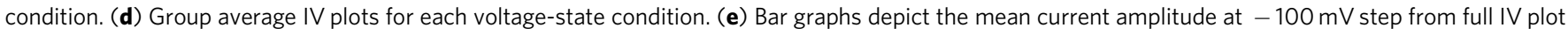
for each condition and were used for statistical comparison between groups ( $n=5-8$ cells per group). (f) Average DAT-mediated current amplitude plotted against the relative mean fraction of original intensity of the YFP-DAT TIRFM footprint (from Fig. 5) for cells patched at control, hyperpolarized and depolarized potentials indicates a positive correlation between increasing DAT-mediated current density and peri-membrane YFP intensity with TIRF microscopy. ${ }^{\#} P<0.05$ using independent samples $t$-test. All values are mean \pm s.e.m.

density in functional neurons, real-time imaging of membrane DAT (TIRFM fluorescence footprint) was coupled with two characterized non-invasive methods (Supplementary Fig. 7) of transient reliable membrane depolarization and hyperpolarization: $100-\mathrm{mM} \mathrm{KCl}$ focal application (Fig. 7a) and archaerhodopsin (Arch) activation (Fig. 7b), respectively. Cultured primary neurons were transfected with TagRFP-T-DAT (RFP-DAT) or CFP-DAT with or without co-transfection with Arch-YFP (Arch-YFP; Supplementary Fig. 7) and were subjected to whole-cell recordings (K-gluconate-based internal solution) or imaging in the presence of tetrodotoxin (TTX) and receptor blocker cocktail (see Methods), unless otherwise indicated. Pressure application of KCl-based external solution induced a reversible $36.9 \pm 8.3-\mathrm{mV}$ membrane depolarization in RFP-DATexpressing neurons (Fig. 7a,c-e), and photo-activation (590 nm) of Arch caused a reversible $-23.3 \pm 3.2-\mathrm{mV}$ membrane hyperpolarization (Fig. 7a,c-e). In the absence of TTX, Arch activation suppressed action potential firing and induced a rebound burst when the light was turned off (Fig. 7b) and was relatively stable over long pulse durations (Supplementary Fig. 7) used for subsequent imaging experiments ${ }^{40}$. The MP of neurons lacking Arch-YFP expression was unaffected by $590-\mathrm{nm}$ light stimulation.

On characterizing the reliability of these tools, we performed simultaneous TIRFM of primary culture neurons (Fig. 7f) during each manipulation (Supplementary Fig. 7b and Fig. 7g,h). TIRFM of neurons expressing RFP-DAT while focally applying $100-\mathrm{mM}$ KCl-based external solution (Supplementary Fig. 7b) for a short duration $(45 \mathrm{~s})$ caused a rapid and dramatic reduction $(-21.1 \pm 8.5 \%)$ in the RFP-DAT TIRFM footprint intensity (Supplementary Movie 2), while vehicle application had no effect (Fig. 7g). Similarly, bath application of 100-mM KCl-based external solution also enhanced the internalization of endogenous DAT in primary neurons labelled with JHC 1-064, causing a dramatic increase in JHC 1-064 complexes in the intracellular space (Supplementary Fig. 8). In contrast, simultaneous MP hyperpolarization via activation of Arch by $590-\mathrm{nm}$ light staggered with TIRFM imaging of CFP-DAT (Fig. 7h) indicated that hyperpolarization caused a reversible increase $(+9.0 \pm 3.5 \%)$ in CFP-DAT intensity in the TIRFM footprint overtime, which stabilized after $120 \mathrm{~s}$ (Fig. $7 \mathrm{~h}$ and Supplementary Movie 3). No significant change $(-3.8 \pm 3.3 \%)$ in CFP-DAT TIRFM footprint intensity was observed in neurons lacking Arch-YFP expression (Fig. 7h). These KCl-induced decreases and Arch activationinduced increases in neuronal cell-surface DAT TIRFM signal, which parallel MP state-dependent changes in the surface density of DAT protein (Figs 1-5) and DAT function (Fig. 6) in YFP-DAT HEK cells, were significantly different from their respective controls (depolarization: $P<0.05$, hyperpolarization: $P<0.05$; Fig. $7 \mathrm{i}$ ). 
a

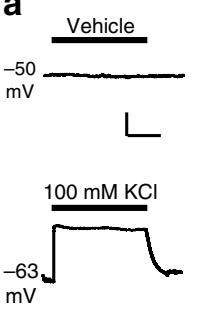

$\mathbf{f}$

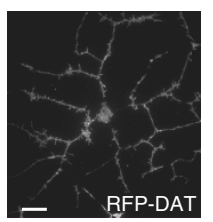

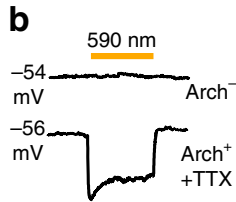
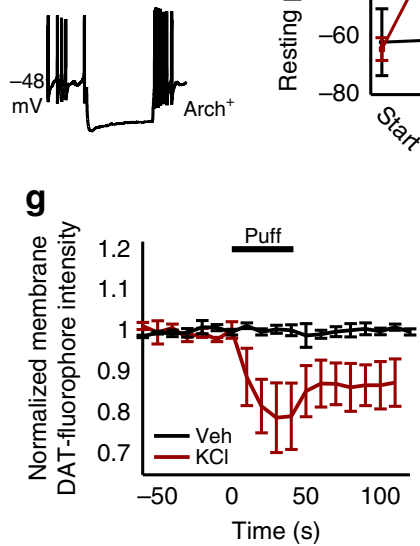

C

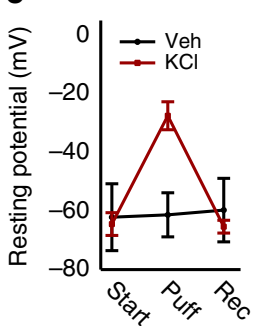

d

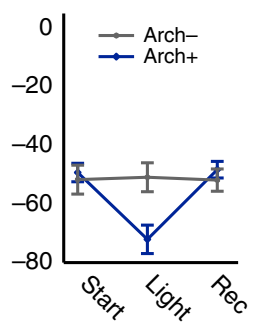

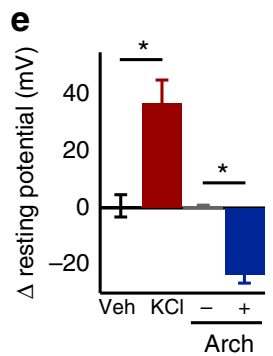

h

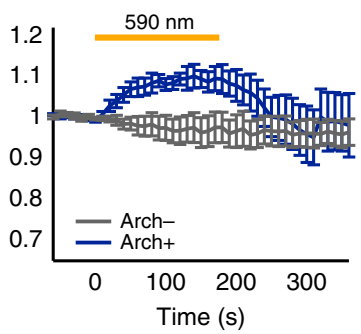

i

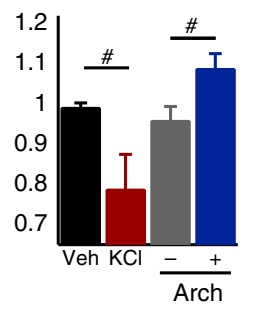

Figure 7 | Neuronal membrane potential rapidly alters membrane-surface DAT level. (a,b) Cultured neuron membrane potential response to (a) vehicle or $100 \mathrm{mM} \mathrm{KCl}$ and (b) $590 \mathrm{~nm}$ stimulation in neurons with/without YFP-Arch $0.5 \mathrm{mM}$ TTX omitted in bottom trace. Scale bar, $10 \mathrm{~s}$ (a) and $500 \mathrm{~ms}$ (b) and

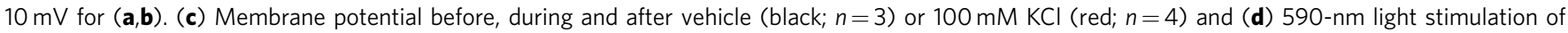
neurons with (blue; $n=13$ )/without (grey; $n=3$ ) Arch-YFP expression. (e) Resting potential change. (f) TIRFM image of primary culture neuron expressing RFP-DAT. (g) The mean normalized intensity of the surface RFP-DAT during vehicle (black; $n=4)$ or $100 \mathrm{mM} \mathrm{KCl}($ red; $n=3$ ) application. (h) The mean normalized intensity of the surface CFP-DAT when a 590-nm light pulse was delivered to cells with (blue; $n=5$ )/without (grey; $n=4$ ) Arch-YFP expression. (i) Normalized somatic membrane RFP- or CFP-DAT fluorescence change for each condition. ${ }^{\#} P<0.05$, ${ }^{\star} P<0.01$ with independent samples t-test.

\section{Discussion}

The presence of DAT at the cell membrane is crucial in the regulation of DAergic signalling, timing and magnitude throughout the brain, and thus any alteration in the functional capacity of the transporter may significantly have an impact on neurological functions in which DA is involved. Previous studies have demonstrated that $\mathrm{KCl}$-induced depolarization reduces $\mathrm{DA}$ uptake $^{30,31}$, and that membrane hyperpolarization increases DAT-mediated inward current and DA uptake ${ }^{13}$, albeit with an unknown mechanism. Here we asked whether changes in MP alone may rapidly and reversibly regulate DAT trafficking. One aspect regulating transporter function is that the trafficking of mature DAT to and from the cell membrane is a highly regulated process, which is affected in various disease states and by the activity of DAT-targeting psychostimulants. Using live cell TIRFM and biotinylation on identically treated HEK cells expressing YFP-DAT, we determined that membrane depolarization alone could induce a CaMKII $\alpha$ - and dynamindependent (Figs 1 and 2) rapid reversible (increase in hyperpolarization recovery) reduction in membrane DAT (Fig. 1 and Supplementary Movie 1). This depolarizationinduced effect on DAT distribution in the TIRFM footprint was distinctly different when compared with the effects of $A M P H$, which did not recover as quickly. Another difference between $\mathrm{AMPH}$ - and depolarization-induced DAT internalization is the insensitivity of AMPH-induced internalization to the loss of CaMKII $\alpha$ activity through the coexpression of a dominantnegative, kinase-inactive CaMKII $\alpha$ (Fig. 2), which, along with the sensitivity of both versions to KN93, may suggest that different isoforms of the kinase may have distinctly different roles in regard to regulating DAT function. Notably, similar fast changes in membrane DAT levels have been reported using this approach with acute AMPH exposure ${ }^{41}$. However, the direction of the AMPH effect on human DAT using the multifaceted approach reported here contrasts with this previous finding and could be due to intrinsic differences between rat and human DAT, AMPH concentrations and/or cell types.

To determine the degree of DAT internalization, with the DAT-specific fluorescent cocaine analogue, JHC 1-064 (ref. 36), we followed the distribution of JHC 1-064 fluorescence (JHC 1-064/DAT complexes; Fig. 3) when cells were left at rest or depolarized. These data suggested that indeed membrane-resident DAT was being more rapidly brought into the intracellular space when depolarized as compared with constitutive internalization (Fig. 3c,d). While biotinylation and confocal imaging inherently lack the temporal resolution of TIRFM, together, results indicate that in contrast to the effects of AMPH on DAT, depolarization resulted in DAT being segregated specifically into early endosome compartments (EEA1), but not recycling endosomes (Rab11; Fig. 4). This divergence in the destination of internalized DAT in cells treated with AMPH versus those simply depolarized again suggests the involvement of differing mechanisms, which may leave initially internalized DAT residing in early endosomes free to transition into rapid recycling endosomes, distinct from recycling endosomes ${ }^{42}$, putatively underlying the faster recovery to the membrane surface during hyperpolarization.

Although few studies have examined DAT activity immediately after depolarization or following the return to the resting hyperpolarized state, our data provide a potential mechanism for the decreased DA uptake in striatal synaptosomes during the fast phase of depolarization-induced DA release ${ }^{31}$. Therefore, to determine any bidirectionality of the $\mathrm{KCl}$ effect on DAT trafficking, we used whole-cell voltage-clamp techniques to clamp the MP of YFP-DAT HEK cells while performing TIRFM simultaneously (Fig. 5). Once cells were clamped near their endogenous resting potential $(-40 \mathrm{mV})$, the YFP-DAT TIRFM footprint was relatively similar over time (Fig. 5c-e). However, when stepping the membrane-holding potential from $-40 \mathrm{mV}$ to a hyperpolarized potential, an increase in YFP-DAT intensity and puncta number in the TIRFM footprint began immediately 
(Fig. 5b) and plateaued after $3 \mathrm{~min}$ (Fig. 5f-h). In contrast, when cells were depolarized the opposite effect occurred with a loss of YFP-DAT signal, which paralleled the effects seen in the presence of depolarizing $\mathrm{KCl}$ (Fig. 5i-k). In fact, the $\sim 10 \%$ change in YFP-DAT intensity directly corresponded to reductions in DAT-mediated (GBR12935-sensitive) current when cells were clamped at depolarized or hyperpolarized potentials (Fig. 6). On the basis of these data and the known electrogenic nature of DAT-mediated DA uptake and efflux, we hypothesize that at depolarized conditions, where efflux is more likely to occur ${ }^{10}$, the cell may actively attenuate this efflux by downregulating DAT at the membrane. In contrast, membrane hyperpolarization, known to facilitate DA uptake ${ }^{13}$, may be doing so through interactions with ionic driving forces and increases in membrane DAT.

With two tools that induced reversible and reliable depolarization (focal $\mathrm{KCl}$ application) or hyperpolarization (Arch activation) of magnitudes, similar to those used in previous experiments (Fig. 7a-e), we used TIRFM to monitor fluorescenttagged DAT expressed in midbrain primary cultures during MP manipulation. The effect of these manipulations on membrane DAT levels were larger than in HEK cells using methods that induced similar voltage differences, implying that these effects are indeed applicable to neuronal populations and results obtained using HEK cells are relevant to shaping conclusions about MP-dependent trafficking of DAT in the nervous system. Together, these data indicate that, while the magnitude of change in membrane DAT levels due to MP changes varies depending on the assay, all changes observed are in a physiologically relevant range and the direction of the effect (increase or decrease) is in agreement across all examinations.

This effect of the MP on DAT trafficking sheds light on an additional mechanism by which the activation of hyperpolarizing $\mathrm{D}_{2}$ Rs may be altering DA transport. The activation of $\mathrm{D}_{2} \mathrm{Rs}$ has long been understood to enhance DAT function ${ }^{43}$, and previous studies have suggested that a $\mathrm{D}_{2} \mathrm{R}$ activation initiates a signalling cascade to upregulate cell-surface $\mathrm{DAT}^{19}$. Although others have examined how changes in the neuronal MP similarly to those initiated by $\mathrm{D}_{2} \mathrm{R}$ activation may alter DAT function and found no impact on $\left[{ }^{3} \mathrm{H}\right]-\mathrm{DA}$ uptake ${ }^{44}$, those experiments were performed at room temperature, which likely attenuates trafficking rates as opposed to the studies here conducted at near-physiological temperatures $\left(37^{\circ} \mathrm{C}\right)$. Thus, this methodological difference may explain the discrepancies between that $\left[{ }^{3} \mathrm{H}\right]$-DA uptake study ${ }^{44}$ relative to the data presented here. Nevertheless, collectively this study and previous studies support the involvement of multifaceted regulatory mechanisms for DAT trafficking that are substrate-, kinase- and activity-dependent. The existence of multiple regulatory mechanisms supports the notion that the DAT proteins at the membrane are responsive to diverse regulatory mechanisms. The overriding mechanism for activation of a given trafficking pathway will be determined by the nature of the stimulation and the availability of specific regulatory constituents.

DA signalling is crucial in many neurological functions, as aberrations in DA neurotransmission contribute to multiple neuropsychiatric disorders, including addiction ${ }^{3,45}$, Parkinson's disease and movement disorders ${ }^{46-48}$, schizophrenia ${ }^{49,50}$ and attention-deficit hyperactivity disorder $(\mathrm{ADHD})^{2}$, all of which have been linked to how extracellular DA may be mishandled by altered DAT expression and function ${ }^{23,50,51}$. As a result, diseaserelated deviations from physiological states and variations in neuronal MPs may be altering the functional capacity of DAT by affecting its trafficking to and from the membrane. This dynamic balance of electrophysiological and biochemical processes to regulate subtle but essential aspects of neurotransmission opens a range of possibilities for exploring related aberrations in disease states and in pharmacotherapy targeting this interaction. Broadly, the regulation of protein (DAT) trafficking by the MP may provide additional means by which plasticity (for example, activity-dependent changes) in DAergic and possibly non-DAergic systems is maintained and controlled.

\section{Methods}

Cell culture. Cell lines. HEK cells overexpressing FLAG-tagged or YFP-tagged human DAT (hDAT), HEK FLAG-DAT (refs 52,53) or YFP-DAT HEK (ref. 54), respectively, were a generous gift from Dr Jonathan Javitch (Colombia University) prepared from HEK293 EM4 as previously described ${ }^{55,56}$. The addition of the YFP tag and FLAG epitope to hDAT is a widely used construct and has not been shown to alter basic functional properties of the transporter or other transporter-mediated activity ${ }^{24,52,53,55,57}$. HEK cells were maintained in DMEM supplemented with $10 \%$ fetal bovine serum (FBS), $5 \%$ L-glutamine, penicillin $\left(50 \mu \mathrm{ml}^{-1}\right)$ and streptomycin $\left(50 \mu \mathrm{ml}^{-1}\right)$ at $37^{\circ} \mathrm{C}$ and $5 \% \mathrm{CO}_{2}$. Cells were typically passaged and/or used for electrophysiology or imaging experiments after reaching $60-80 \%$ of full confluency (every 2-3 days). To induce expression of constructs not stably expressed in HEK cell lines, HEK293 EM4 cells were transfected using a standard calcium phosphate protocol. Transfected cells were used in experiments $12-36 \mathrm{~h}$ after transfection.

Midbrain primary neuron culture. All animals used were housed in the University of Florida's McKnight Brain Institute animal care facility, an Association for Assessment and Accreditation of Laboratory Animal Care International-accredited facility. The University of Florida's Institutional Animal Care and Use Committee approved of all procedures undertaken. Primary cultures of the ventral midbrain containing DAergic neurons were prepared as previously described $^{9,57,58}$ and are described here in brief. The ventral midbrain, including DA neuron-rich regions, was acutely dissociated and isolated under sterile conditions from 0- to 2-day-old C57Bl/6 $\mathrm{J}$ mice of both sexes and incubated at $34-36^{\circ} \mathrm{C}$ under continuous oxygenation for $30 \mathrm{~min}$ in a dissociation medium, containing (in $\mathrm{mM}$ ) $116 \mathrm{NaCl}, 5.4 \mathrm{KCl}, 26 \mathrm{NaHCO}_{3}, 25$ glucose, $2 \mathrm{NaH}_{2} \mathrm{PO}_{4}, 1 \mathrm{MgSO}_{4}, 1.3$ cysteine, 0.5

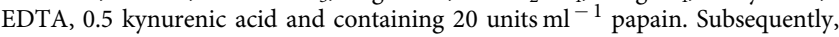
tissue was triturated with fire-polished Pasteur pipettes in glial medium, containing (in \%): $50 \mathrm{MEM}, 38.5 \mathrm{FBS}, 7.7$ penicillin/streptomycin, $2.9 \mathrm{D}$-glucose (45\%) and 0.9 glutamine $(200 \mathrm{mM})$. Dissociated cells were pelleted at $450 \mathrm{~g}$ for $10 \mathrm{~min}$ and were re-suspended in glial medium. Cells were plated on 12-mm round coverslips placed in $35 \times 10 \mathrm{~mm}$ style tissue culture Petri dishes or glass-bottom $35 \times 10 \mathrm{~mm}$ (MatTek, Ashland, MA) coated with $100 \mu \mathrm{g} \mathrm{ml}^{-1}$ poly-D-lysine and $5 \mu \mathrm{g} \mathrm{ml}^{-1}$ laminin. One hour after plating, the medium was changed to neuronal medium, containing (in \%): 2 MEM, 75 Ham's-F12 medium, 19 heat-inactivated horse serum, 2 FBS, $1.56 \mathrm{D}$-glucose $(45 \%), 0.04$ insulin $\left(0.025 \mathrm{~g} \mathrm{ml}^{-1}\right)$ and 0.4 apotransferrin $\left(50 \mathrm{mg} \mathrm{ml}^{-1}\right)$. Neuronal cultures were transfected with TAGRFP-T-DAT, CFP-DAT and/or Arch-YFP constructs via nucleofection (Mouse Nucleofector Kit, programme O-005, Lonza Group Ltd, Basel, Switzerland) immediately before plating or via calcium phosphate 3-5 days after plating using standard protocols. All cultures were used at $7-9$ days in vitro (DIV) and 4-9 days post transfection. No difference between transfection methodologies was observed regarding protein expression level and/or function.

Plasmid constructs. The plasmid coding for the cyan fluorescent protein-tagged DAT was described previously ${ }^{59,60}$ and was provided as a generous gift from Dr Alexander Sorkin (University of Pittsburgh). The RFP-tagged hDAT (TagRFP-T-DAT) $^{34}$, generated as previously described, was a gift from Dr Haley Melikian (University of Massachusetts), and the construct for fatty-acid receptor GPR40-eYFP driven by the cytomegalovirus promoter was a gift from Dr Sergei Zolotukhin and Seth Currlin (University of Florida). DsRed-Rab11 WT ${ }^{61}$, a recycling endosome marker, was a gift from Richard Pagano (Mayo Clinic and Foundation, Addgene plasmid \#12679). TagRFP-T-EEA1 (ref. 62), an early endosome marker, was provided by Silvia Corvera (University of Massachusetts Medical School, Addgene plasmid \#42635). The GFP-C1-CAMKII $\alpha$-K42R (ref. 63) was a gift from Tobias Meyer (Stanford University, Addgene plasmid \#21221), and the pTfR-PAmCherryl (ref. 64) plasmid was a gift from Vladislav Verkhusha (Albert Einstein College of Medicine, Addgene plasmid \#31948). To confer optical control of MP hyperpolarization, neuronal cultures were transfected with AAV-CaMK $\alpha$-eArch 3.0-EYFP plasmid, a generous gift from Dr Karl Deisseroth (Stanford University). Arch was chosen for its ability to induce large magnitude $\mathrm{H}^{+}$-current-hyperpolarizing shifts $(10-50 \mathrm{mV})$ in the neuronal MP, which were relatively stable over seconds to minutes with minimal decay when continuously activated ${ }^{40,65}$

Electrophysiology. HEK cells and cultured neurons were visualized with a $\times 60$ objective on an inverted Nikon Ti Eclipse microscope (Nikon, Melville, NY). All currents and MPs were recorded via an Axoclamp 200A amplifier using the whole-cell configuration after forming a high-resistance seal in the cell-attached configuration $(>1 \mathrm{M} \Omega)$. All signals were digitized with a Digidata $1440 \mathrm{~A}$ at $10 \mathrm{kHz}$, and a $5-\mathrm{kHz}$ low-pass Bessel filter was applied during acquisition. An additional $2-\mathrm{kHz}$ Gaussian filter was applied to all traces for presentation only. 
The standard external solution for electrophysiology experiments using HEK cells was the same used in all microscopy and biochemistry experiments and contained (in $\mathrm{mM}$ ) the following: $130 \mathrm{NaCl}, 10 \mathrm{HEPES}, 34$ Dextrose, $1.5 \mathrm{CaCl}_{2}, 0.5 \mathrm{MgSO}_{4}$ and $1.3 \mathrm{KH}_{2} \mathrm{PO}_{4}$, with a pH of 7.35 and osmolarity of $275-290$ mOsm. Pipettes for whole-cell recordings were pulled from borosilicate glass on a P-2000 laser-based puller (Sutter Instruments, Novato, CA). Pipettes used for recording the MP (3-6 M 2 ) were filled with an internal solution containing (in $\mathrm{mM}$ ) the following: $130 \mathrm{~K}$-gluconate, $10 \mathrm{KCl}, 10 \mathrm{HEPES}, 1 \mathrm{EGTA}, 2 \mathrm{MgCl}_{2}$ adjusted to $\mathrm{pH} 7.35$ and osmolarity of $262 \mathrm{mOsm}$. For recording of DAT-mediated whole-cell currents, pipettes were filled with (in $\mathrm{mM}$ ) the following: $120 \mathrm{CsCl}, 30$ dextrose, $10 \mathrm{HEPES}$, 1.1 EGTA, $2 \mathrm{MgCl}_{2}$ and $0.1 \mathrm{CaCl}_{2}$ adjusted to $\mathrm{pH} 7.35$ and osmolarity of $264 \mathrm{mOsm}$. Recordings were performed at $37^{\circ} \mathrm{C}$. For determining DAT-mediated current and IV changes at different holding potentials, a stable IV $(-100$ to +40 in $20 \mathrm{mV}$ steps) was generated after $5 \mathrm{~min}$ of continuously holding the cell at the given potential $(-60,-40$ or $+20 \mathrm{mV})$, and then the DAT blocker GBR12935 $(20 \mu \mathrm{M})$ was added to the bath and subsequent IVs were measured every 30-60 s. To determine the DAT-mediated current amplitude, the IV in the presence of GBR12935 (Fig. 6c; protocol \#2; grey traces) was subtracted from the preGBR12935 IV following the prolonged clamp of the MP (Fig. 6 c; protocol \#1; red $=+20 \mathrm{mV}$, black $=-40 \mathrm{mV}$, blue $=-60 \mathrm{mV}$ ) to yield the DAT-mediated (GBR12935sensitive) current at each voltage step of the IV (the curve displayed in Fig. 6d) corresponding with manipulation of the MP state in previous TIRFM experiments (Fig. 5). For statistical comparisons between groups (Fig. 6e,f), the DAT-mediated current (pre-GBR12935-post-GBR12935 amplitude) at the $-100 \mathrm{mV}$ step, where DAT-mediated current is largest, was used.

For recording and imaging of DAergic neurons in primary culture, the external solution contained (in $\mathrm{mM}$ ) the following: $146 \mathrm{NaCl}, 5 \mathrm{HEPES}, 5 \mathrm{KCl}, 30$ Dextrose, $2.5 \mathrm{CaCl}_{2}$ and $1.2 \mathrm{MgCl}_{2}$, with $\mathrm{pH} 7.35$ and had an osmolarity of $290-300 \mathrm{mOsm}$. Patch pipettes (4-6 M 2 ) were filled with an internal solution containing the following (in $\mathrm{mM}$ ): $135 \mathrm{~K}$-gluconate, $5 \mathrm{KCl}, 2 \mathrm{MgCl}_{2}, 10$ HEPES, 0.1 EGTA, $2 \mathrm{Mg}$-ATP and $0.2 \mathrm{Na}-\mathrm{GTP}, \mathrm{pH}$ adjusted to 7.35 and osmolarity of $270 \mathrm{mOsm}$. Recordings of the neuronal MP were corrected offline for a calculated liquid junction potential of $16.1 \mathrm{mV}$. All recordings occured at $37^{\circ} \mathrm{C}$.

Microscopy. All microscopy analyses were performed at $37^{\circ} \mathrm{C}$, and cells were washed twice with external solution as described above before all experiments. For all imaging experiments, cells/neurons were set on 35-mm glass-bottom dishes (MatTek, Ashland, MA) with glass thickness of $0.13-0.16 \mathrm{~mm}$ (TIRFM) or $0.085-0.13 \mathrm{~mm}$ (confocal). Wide-field fluorescence images were acquired identically to TIRFM images; however, a Lambda LS Xenon Arc Lamp provided the light source that bypassed the additional TIRFM mirror set and was passed through appropriate excitation (Ex)/emission (Em) filters and dichroic mirror. Microscopy data were analysed in the Nikon's NIS Elements software.

TIRFM. TIRFM imaging of HEK cells and neurons plated on poly-d-lysinecoated dishes was performed at $37^{\circ} \mathrm{C}$ using Nikon Eclipse TE-2000-U inverted microscope, with a $\times 601.49$ numerical aperture (NA) objective and equipped with a multiline solid-state laser system $(470,514$ and $561 \mathrm{~nm})$ and appropriate filter combination for YFP (Ex: $514 \mathrm{~nm} / \mathrm{Em}: 535 \mathrm{~nm}$ ), TagRFP (Ex: $561 \mathrm{~nm} / \mathrm{Em}$ : $584 \mathrm{~nm}$ ) and CFP (Ex: $445 \mathrm{~nm} / \mathrm{Em}: 475 \mathrm{~nm}$ ), similar to as previously described ${ }^{57}$ TIRFM was achieved via the 'through-the-objective' laser guidance method with the laser incident angle set to $76^{\circ}$, which is greater than the critical angle of $62^{\circ}$ and generated an evanescent field depth between 66 and $72 \mathrm{~nm}$ depending on the wavelength of light used. Temperature control was maintained with a stage and an objective heater (20/20 Technology Inc.). Image exposure time was coupled with laser excitation duration at $200-300 \mathrm{~ms}$, and laser intensity was maintained at $40-60 \%$ of maximum intensity, but neither changed throughout the course of a given experiment. Images were detected digitally using an attached CoolSNAP $\mathrm{HQ}^{2}$ CCD camera and stored on a computer hard drive at 5-10-s intervals. For imaging of HEK cells, baseline images were acquired during perfusion of standard external solution before changing the solution to $100-\mathrm{mM} \mathrm{KCl}$-based external solution (osmotically balanced) or $10 \mu \mathrm{M} \mathrm{AMPH}$, prepared as described above, or throughout the entirety of being held in the whole-cell configuration. For simultaneous patch-clamp and TIRFM, membrane-holding potentials of +20 , -40 and $-60 \mathrm{mV}$ were determined in preliminary experiments to approximate endogenous resting potential of these cells $(-40 \mathrm{mV})$, to mimic the effects of $100-$ $\mathrm{m} \mathrm{KCl}$ depolarization $(+20 \mathrm{mV})$ and to oppose depolarizing effects of $+20 \mathrm{mV}$ with a similar magnitude of change $(-60 \mathrm{mV})$

For quantification of cell-surface fluorescence intensity of isolated HEK cells and primary culture neurons, regions of interest were created, including the TIRFM footprint of each HEK cell in its entirety or the neuron's soma. For all image sequences, a background ROI similar to the size of a cell was placed in a region devoid of cells/fluorescence and was subtracted from the entire image and recalculated for each frame. The mean intensity (in arbitrary fluorescent units) over time was monitored and plotted/analysed as a fraction of the baseline intensity (the mean raw intensity of all frames within 30-60s before initiation of indicated manipulation) and used for analysis. Bleaching was controlled for in two ways. The first was the inclusion of a vehicle group and/or non-patched adjacent cells for each assay appropriately. However, because of relatively large observed cell-to-cell variability in the change in baseline fluorescence over time ranging from -3.0 to $+2.1 \%$ per min (average $0.4 \pm 0.3 \%$ per $\mathrm{min}$ ), a correction factor or rate was determined for each cell and was used to account for this change in each cell. Since the bleaching rate with the current TIRFM imaging parameters was linear, a linear fit was generated for $120 \mathrm{~s}$ before a solution change and was used to determine that the rate of bleaching was extrapolated over the entire 12-15-min experiment. This projected rate of change in fluorescence intensity due to bleaching was then accounted for during each experiment.

Confocal microscopy and JHC 1-064 labelling of DAT. Imaging of YFP-DAT (ex: $514 \mathrm{~nm}$, em: 540/30 nm), mCherry, dsRed and JHC 1-064 (all ex: $561 \mathrm{~nm}$, em: 585/ $65 \mathrm{~nm}$ ) was performed using the Nikon A1R confocal system mounted on a Nikon Eclipse Ti-E inverted microscope (Nikon) using a $\times 601.49$ NA Plan-Apo objective (Nikon). For YFP-DAT and endosome co-localization experiments, YFPDAT HEK cells grown on glass-bottom dishes and transfected with TagRFP-TEEA1 or DsRed-Rab11 were treated with either $100 \mathrm{mM} \mathrm{KCl}$ for $5 \mathrm{~min}, 10 \mu \mathrm{M}$ AMPH for $1 \mathrm{~h}$ or with standard external solution vehicle throughout all the experiments at $37^{\circ} \mathrm{C}$. After the treatment, the dishes were placed on ice and washed with the ice-cold standard external solution, then washed two more times with ice-cold PBS solution and then fixed in 3.7\% paraformaldehyde. Cells were then washed and imaged using identical imaging parameters (for example, laser power, gain, and so on) immediately in PBS. For co-localization analysis, a region of interest (ROI) was drawn over the intracellular space of each cell in the raw image and the Pearson correlation coefficient for the two channels was calculated on a cell-by-cell basis in NIS Elements (Nikon). For clarity and image display only, a single-count $3 \times 3$ pixel matrix smooth was applied, and intensity of all pixels was enhanced by $40 \%$.

The fluorescent cocaine analogue, JHC 1-064, which has a high affinity for DAT, was used as previously described to selectively label membrane-resident DAT $35,36,38,66$. When YFP-DAT HEK cells had reached $60-80 \%$ confluency after 2-3 days or midbrain primary culture neurons had reached DIV 5 , they were washed twice with the appropriate standard external solution and incubated with 10-20 nM JHC 1-064 for a minimum of $30 \mathrm{~min}$ at $4^{\circ} \mathrm{C}$. After at least $30 \mathrm{~min}$, the JHC 1-064-containing solution was removed and replaced with fresh $4{ }^{\circ} \mathrm{C}$ external solution. Immediately, the dish was placed on the stage, and cells were selected and a baseline image was acquired. Following acquisition, the cold solution was removed and replaced with either vehicle or $\mathrm{KCl}$-based external solution at $37^{\circ} \mathrm{C}$, and images were acquired every $5 \mathrm{~min}$. Imaging parameters (for example, laser power, gain, pinhole, and so on) were identical for images of HEK cells and were within the imaging series of each neuron. For analysis of JHC 1-064/DAT complexes in HEK cells, an area devoid of cells was selected and used as a background ROI, and the mean pixel intensity of this region was subtracted from intensity of all pixels. For determination of the mean intracellular intensity, an ROI was drawn within the boundaries of each cell and the mean intensity (normalizing for changes in cell size) was again normalized to the intensity of the entire image to account for bleaching and was plotted as a fraction of the initial internal fluorescence in the original control $4^{\circ} \mathrm{C}$ image ${ }^{67}$. For manual counts of intracellular JHC 1-064 puncta and clarity for display (Fig. 3 and Supplementary Fig. 8), all images were processed identically.

Biotinylation assay. For biotinylation assays, YFP-DAT HEK cells or parental HEK293 cells were plated on 24-well poly-D-lysine-coated plates at a density of $2 \times 10^{5}$ cells per well and transfected with either GFP-C1-CaMKII $\alpha-K 42 \mathrm{R}$ or pTfR-PAmCherryl, as previously described ${ }^{68}$. Forty-eight to ninety-six hours after plating, cells were pre-treated $(30 \mathrm{~min})$ with external solution (vehicle) or $80 \mu \mathrm{M}$ Dynasore, followed by 30 -min treatment with vehicle, vehicle $+10 \mu \mathrm{M}$ KN92 or vehicle $+10 \mu \mathrm{MKN} 93$. Cells were then washed and treated for $5 \mathrm{~min}$ with either vehicle, $10 \mu \mathrm{M}$ AMPH, $2.5 \mu \mathrm{M}$ PMA, iso-osmotic $50 \mathrm{mM} \mathrm{KCl}$, iso-osmotic $100 \mathrm{mM}$ $\mathrm{KCl}, 100 \mathrm{mM} \mathrm{KCl}+\mathrm{KN} 92$ or $100 \mathrm{mM} \mathrm{KCl}+\mathrm{KN} 93$. Cell-surface proteins were then biotinylated and analysed via western blot analysis as described previously ${ }^{69}$ Total protein concentrations for each sample were determined using the Pierce BCA protein assay kit (Thermo Scientific), and the resulting values were used to load equal amounts of protein for each sample when conducting SDS-PAGE. Blots of total and surface protein (Supplementary Figs $4 \mathrm{c}, \mathrm{d}$ and $5 \mathrm{c}$ for original blots) were probed with an N-terminal-targeted anti-DAT monoclonal antibody $(1: 1,000$; mAb16 (ref. 70); a gift from Dr Roxanne Vaughan of the University of North Dakota) or an anti-transferrin receptor antibody (1:1,000; C2F2, BD Biosciences), and the density of the immunoblot bands was quantitated using Image (NIH) or Image Studio (LI-COR). Prism5 (GraphPad) was used for statistical analysis following normalization of surface values to vehicle and determination of the vehicle variance by normalizing to AMPH.

Drug/solution application and optical stimulation. In electrophysiology, microscopy and biochemistry experiments, increased $\mathrm{KCl}$ concentrations $(100 \mathrm{mM})$ were achieved by replacing $\mathrm{NaCl}$ in the standard external solution or ACSF with $\mathrm{KCl}$ in an equa-molar manner, conserving osmolarity. For TIRFM imaging of HEK cells, vehicle (standard external solution), the KCl-based external solution or $10 \mu \mathrm{M}$ AMPH was applied via bath perfusion using a laminar flow insert for 35-mm Petri dishes at a rate of $2 \mathrm{ml} \mathrm{min}^{-1}$. For neuronal recordings and TIRF microscopy, vehicle or KCl-based external solution was applied via pressure $(2 \mathrm{psi})$ injection from a pipette identical to recording pipettes positioned $20 \mu \mathrm{m}$ from the cell body. HEK293 or YFP-DAT HEK cells were exposed to either $80 \mu \mathrm{M}$ dynasore $^{34}$ (Thermo Fisher Scientific), $10 \mu \mathrm{M}$ KN92, $10 \mu \mathrm{M}$ KN93 or $10 \mu \mathrm{M}$ BIM 
(all from EMD Millipore) for 25-30 min before and throughout treatment with vehicle or $100 \mathrm{mM} \mathrm{KCl}$ to maintain the respective inhibition of dynamin, CaMK and PKC throughout each imaging or biotinylation experiment as indicated.

For steady-state photo-activation of eArch3.0 in cultured neurons, 590-nm light was generated from a light-emitting diode (LED) source (Thorlabs) and coupled to an optical fibre and placed at a 45 degree angle, with the tip 150-200 $\mu \mathrm{m}$ from the cell body. The output at the fibre tip $(200 \mu \mathrm{m}$ diameter) was regulated via a potentiometer on the externally-triggered LED driver and was calibrated so that the light power density at the tip was $15 \mathrm{~mW} \mathrm{~mm}^{-2}$. Changes in MP in response to eArch 3.0 activation were determined by taking the average MP over $50 \mathrm{~ms}$ before light onset and the last $50 \mathrm{~ms}$ of a 1-s light pulse.

Data analysis. All data were analysed with Microsoft Excel, IBM SPSS, Prism5 or Igor Pro. Statistical analyses used for comparison are identified in the legend, and all values are the mean \pm s.e.m., unless otherwise stated.

\section{References}

1. Schultz, W. Multiple dopamine functions at different time courses. Annu. Rev. Neurosci. 30, 259-288 (2007).

2. Nieoullon, A. Dopamine and the regulation of cognition and attention. Prog. Neurobiol. 67, 53-83 (2002).

3. Koob, G. F. \& Volkow, N. D. Neurocircuitry of addiction. Neuropsychopharmacology 35, 217-238 (2010).

4. Jaber, M., Robinson, S. W., Missale, C. \& Caron, M. G. Dopamine receptors and brain function. Neuropharmacology 35, 1503-1519 (1996).

5. Mundorf, M. L., Troyer, K. P., Hochstetler, S. E., Near, J. A. \& Wightman, R. M. Vesicular $\mathrm{Ca}(2+)$ participates in the catalysis of exocytosis. J. Biol. Chem. 275, 9136-9142 (2000).

6. Beaulieu, J.-M. \& Gainetdinov, R. R. The physiology, signaling, and pharmacology of dopamine receptors. Pharmacol. Rev. 63, 182-217 (2011).

7. Jaber, M., Jones, S., Giros, B. \& Caron, M. G. The dopamine transporter: a crucial component regulating dopamine transmission. Mov. Disord. 12, 629-633 (1997)

8. Sitte, H. H. et al. Carrier-mediated release, transport rates, and charge transfer induced by amphetamine, tyramine, and dopamine in mammalian cells transfected with the human dopamine transporter. J. Neurochem. 71, 1289-1297 (1998).

9. Kahlig, K. M. et al. Amphetamine induces dopamine efflux through a dopamine transporter channel. Proc. Natl Acad. Sci. USA 102, 3495-3500 (2005).

10. Khoshbouei, H., Wang, H., Lechleiter, J. D., Javitch, J. A. \& Galli, A Amphetamine-induced dopamine efflux. A voltage-sensitive and intracellular $\mathrm{Na}+$-dependent mechanism. J. Biol. Chem. 278, 12070-12077 (2003).

11. Amara, S. G. \& Sonders, M. S. Neurotransmitter transporters as molecular targets for addictive drugs. Drug Alcohol Depend. 51, 87-96 (1998).

12. DeFelice, L. J. \& Galli, A. Electrophysiological analysis of transporter function. Adv Pharmacol 42, 186-190 (1998).

13. Sonders, M. S., Zhu, S. J., Zahniser, N. R., Kavanaugh, M. P. \& Amara, S. G. Multiple ionic conductances of the human dopamine transporter: the actions of dopamine and psychostimulants. J. Neurosci. 17, 960-974 (1997).

14. Ingram, S. L., Prasad, B. M. \& Amara, S. G. Dopamine transporter-mediated conductances increase excitability of midbrain dopamine neurons. Nat. Neurosci. 5, 971-978 (2002).

15. Schmitt, K. C. \& Reith, M. E. a. Regulation of the dopamine transporter: aspects relevant to psychostimulant drugs of abuse. Ann. N Y Acad. Sci. 1187, 316-340 (2010).

16. Mortensen, O. V. \& Amara, S. G. Dynamic regulation of the dopamine transporter. Eur. J. Pharmacol. 479, 159-170 (2003).

17. Pristupa, Z. B. et al. Protein kinase-mediated bidirectional trafficking and functional regulation of the human dopamine transporter. Synapse 30, 79-87 (1998).

18. Sorkina, T., Hoover, B. R., Zahniser, N. R. \& Sorkin, A. Constitutive and protein kinase $\mathrm{C}$-induced internalization of the dopamine transporter is mediated by a clathrin-dependent mechanism. Traffic 6, 157-170 (2005).

19. Moron, J. A. et al. Mitogen-activated protein kinase regulates dopamine transporter surface expression and dopamine transport capacity. J. Neurosci. 23, 8480-8488 (2003).

20. Wei, Y. et al. Dopamine transporter activity mediates amphetamine-induced inhibition of Akt through a Ca2 +/calmodulin-dependent kinase II-dependent mechanism. Mol. Pharmacol. 71, 835-842 (2007).

21. Cremona, M. L. et al. Flotillin-1 is essential for PKC-triggered endocytosis and membrane microdomain localization of DAT. Nat. Neurosci. 14, 469-477 (2011).

22. Adkins, E. M. et al. Membrane mobility and microdomain association of the dopamine transporter studied with fluorescence correlation spectroscopy and fluorescence recovery after photobleaching. Biochemistry 46, 10484-10497 (2007).
23. Sakrikar, D. et al. Attention deficit/hyperactivity disorder-derived coding variation in the dopamine transporter disrupts microdomain targeting and trafficking regulation. J. Neurosci. 32, 5385-5397 (2012).

24. Kahlig, K. M. \& Galli, A. Regulation of dopamine transporter function and plasma membrane expression by dopamine, amphetamine, and cocaine. Eur. J. Pharmacol. 479, 153-158 (2003).

25. Zahniser, N. R. \& Sorkin, A. Rapid regulation of the dopamine transporter: role in stimulant addiction? Neuropharmacology 47(Suppl 1): 80-91 (2004)

26. Chi, L. \& Reith, M. E. A. Substrate-induced trafficking of the dopamine transporter in heterologously expressing cells and in rat striatal synaptosomal preparations. J. Pharmacol. Exp. Ther. 307, 729-736 (2003).

27. Zahniser, N. R. \& Sorkin, A. Trafficking of dopamine transporters in psychostimulant actions. Semin. Cell Dev. Biol. 20, 411-417 (2009).

28. Saunders, C. et al. Amphetamine-induced loss of human dopamine transporter activity: an internalization-dependent and cocaine-sensitive mechanism. Proc. Natl Acad. Sci. USA 97, 6850-6855 (2000).

29. Daws, L. C. et al. Cocaine increases dopamine uptake and cell surface expression of dopamine transporters. Biochem. Biophys. Res. Commun. 290, 1545-1550 (2002).

30. Woodward, J. J., Wilcox, R. E., Leslie, S. W. \& Riffee, W. H. Dopamine uptake during fast-phase endogenous dopamine release from mouse striatal synaptosomes. Neurosci. Lett. 71, 106-112 (1986).

31. Holz, R. W. \& Coyle, J. T. The effects of various salts, temperature, and the alkaloids veratridine and batrachotoxin on the uptake of $[3 \mathrm{H}]$ dopamine into synaptosomes from rat striatum. Mol. Pharmacol. 10, 746-758 (1974).

32. Sorkina, T., Richards, T. L., Rao, A., Zahniser, N. R. \& Sorkin, A. Negative regulation of dopamine transporter endocytosis by membrane-proximal N-terminal residues. J. Neurosci. 29, 1361-1374 (2009).

33. La Sala, M. S. et al. Modulation of taste responsiveness by the satiation hormone peptide YY. FASEB J. 27, 5022-5033 (2013).

34. Gabriel, L. R. et al. Dopamine transporter endocytic trafficking in striatal dopaminergic neurons: differential dependence on dynamin and the actin cytoskeleton. J. Neurosci. 33, 17836-17846 (2013).

35. Cha, J. H. et al. Rhodamine-labeled 2beta-carbomethoxy-3beta(3,4-dichlorophenyl)tropane analogues as high-affinity fluorescent probes for the dopamine transporter.. J. Med. Chem. 48, 7513-7516 (2005).

36. Eriksen, J. et al. Visualization of dopamine transporter trafficking in live neurons by use of fluorescent cocaine analogs. J. Neurosci. 29, 6794-6808 (2009).

37. Hong, W. C. \& Amara, S. G. Differential targeting of the dopamine transporter to recycling or degradative pathways during amphetamine- or PKC-regulated endocytosis in dopamine neurons. FASEB J. 27, 1-13 (2013).

38. Eriksen, J., Bjørn-Yoshimoto, W. E., Jørgensen, T. N., Newman, A. H. \& Gether, U. Postendocytic sorting of constitutively internalized dopamine transporter in cell lines and dopaminergic neurons. J. Biol. Chem. 285, 27289-27301 (2010).

39. Rao, A., Simmons, D. \& Sorkin, A. Differential subcellular distribution of endosomal compartments and the dopamine transporter in dopaminergic neurons. Mol. Cell Neurosci. 46, 148-158 (2011).

40. Mattis, J. et al. Principles for applying optogenetic tools derived from direct comparative analysis of microbial opsins. Nat. Methods 9, 159-172 (2012)

41. Furman, C. A. et al. Dopamine and amphetamine rapidly increase dopamine transporter trafficking to the surface: live-cell imaging using total internal reflection fluorescence microscopy. J. Neurosci. 29, 3328-3336 (2009).

42. Grant, B. D. \& Donaldson, J. G. Pathways and mechanisms of endocytic recycling. Nat. Rev. Mol. Cell Biol. 10, 597-608 (2009).

43. Meiergerd, S. M., Patterson, T. A. \& Schenk, J. O. D2 receptors may modulate the function of the striatal transporter for dopamine: kinetic evidence from studies in vitro and in vivo. J. Neurochem. 61, 764-767 (1993).

44. Prasad, B. M. \& Amara, S. G. The dopamine transporter in mesencephalic cultures is refractory to physiological changes in membrane voltage. J. Neurosci. 21, 7561-7567 (2001).

45. Kalivas, P. W. Neurobiology of cocaine addiction: implications for new pharmacotherapy. Am. J. Addict. 16, 71-78 (2007).

46. Vernier, P. et al. The degeneration of dopamine neurons in Parkinson's disease: insights from embryology and evolution of the mesostriatocortical system. Ann. N Y Acad. Sci. 1035, 231-249 (2004).

47. Kurian, M. A. et al. Clinical and molecular characterisation of hereditary dopamine transporter deficiency syndrome: an observational cohort and experimental study. Lancet Neurol. 10, 54-62 (2011).

48. Hansen, F. H. et al. Missense dopamine transporter mutations associate with adult parkinsonism and ADHD. J. Clin. Invest. 124, 3107-3120 (2014).

49. Lodge, D. J. \& Grace, A. A. Developmental pathology, dopamine, stress and schizophrenia. Int. J. Dev. Neurosci. 29, 207-213 (2011).

50. Cordeiro, Q., Siqueira-Roberto, J. \& Vallada, H. Association between the SLC6A3 A1343G polymorphism and schizophrenia. Arq. Neuropsiquiatr. 68, 716-719 (2010). 
51. Madras, B. K., Miller, G. M. \& Fischman, A. J. The dopamine transporter: relevance to attention deficit hyperactivity disorder (ADHD). Behav. Brain Res. 130, 57-63 (2002).

52. Hastrup, H., Karlin, A. \& Javitch, J. A. Symmetrical dimer of the human dopamine transporter revealed by cross-linking Cys-306 at the extracellular end of the sixth transmembrane segment. Proc. Natl Acad. Sci. USA 98, 10055-10060 (2001)

53. Hastrup, H., Sen, N. \& Javitch, J. A. The human dopamine transporter forms a tetramer in the plasma membrane: cross-linking of a cysteine in the fourth transmembrane segment is sensitive to cocaine analogs. J. Biol. Chem. 278, 45045-45048 (2003)

54. Kahlig, K. M., Javitch, J. A. \& Galli, A. Amphetamine regulation of dopamine transport. Combined measurements of transporter currents and transporter imaging support the endocytosis of an active carrier. J. Biol. Chem. 279, 8966-8975 (2004).

55. Goodwin, J. S. et al. Amphetamine and methamphetamine differentially affect dopamine transporters in vitro and in vivo. J. Biol. Chem. 284, 2978-2989 (2009).

56. Eshleman, A. J., Henningsen, R. A., Neve, K. A. \& Janowsky, A. Release of dopamine via the human transporter. Mol. Pharmacol. 45, 312-316 (1994).

57. Saha, K. et al. Intracellular methamphetamine prevents the dopamine-induced enhancement of neuronal firing. J. Biol. Chem. 289, 22246-22257 (2014).

58. Fog, J. U. et al. Calmodulin kinase II interacts with the dopamine transporter C terminus to regulate amphetamine-induced reverse transport. Neuron 51, 417-429 (2006).

59. Sorkina, T., Doolen, S., Galperin, E., Zahniser, N. R. \& Sorkin, A. Oligomerization of dopamine transporters visualized in living cells by fluorescence resonance energy transfer microscopy. J. Biol. Chem. 278, 28274-28283 (2003).

60. Miranda, M., Wu, C. C., Sorkina, T., Korstjens, D. R. \& Sorkin, A. Enhanced ubiquitylation and accelerated degradation of the dopamine transporter mediated by protein kinase C. J. Biol. Chem. 280, 35617-35624 (2005).

61. Choudhury, A. et al. Rab proteins mediate Golgi transport of caveolainternalized glycosphingolipids and correct lipid trafficking in Niemann-Pick C cells. J. Clin. Invest. 109, 1541-1550 (2002).

62. Navaroli, D. M. et al. Rabenosyn-5 defines the fate of the transferrin receptor following clathrin-mediated endocytosis. Proc. Natl Acad. Sci. USA 109, E471-E480 (2012).

63. Shen, K. \& Meyer, T. Dynamic control of CaMKII translocation and localization in hippocampal neurons by NMDA receptor stimulation. Science 284, 162-166 (1999).

64. Subach, F. V. et al. Photoactivatable mCherry for high-resolution two-color fluorescence microscopy. Nat. Methods 6, 153-159 (2009).

65. Zhang, F. et al. The microbial opsin family of optogenetic tools. Cell 147, 1446-1457 (2011)

66. Rickhag, M. et al. Membrane permeable C-terminal dopamine transporter peptides attenuate amphetamine-evoked dopamine release. J. Biol. Chem. 288, 27534-27544 (2013).
67. Kahlig, K. M. et al. Regulation of dopamine transporter trafficking by intracellular amphetamine. Mol. Pharmacol. 70, 542-548 (2006).

68. Dahal, R. A. et al. Computational and biochemical docking of the irreversible cocaine analog RTI 82 directly demonstrates ligand positioning in the dopamine transporter central substrate-binding site. J. Biol. Chem. 289, 29712-29727 (2014).

69. Felts, B. et al. The two $\mathrm{Na}+$ sites in the human serotonin transporter play distinct roles in the ion coupling and electrogenicity of transport. J. Biol. Chem. 289, 1825-1840 (2014).

70. Foster, J. D., Pananusorn, B., Cervinski, M. A., Holden, H. E. \& Vaughan, R. A. Dopamine transporters are dephosphorylated in striatal homogenates and in vitro by protein phosphatase 1. Brain Res. Mol. Brain Res. 110, 100-108 (2003).

\section{Acknowledgements}

We thank Dr Min Lin for assistance and direction in preparation of midbrain neuron primary culture and Sean Olson for his assistance in preparing plasmid DNA. This study was funded by NIH grant \# DA026947, NS071122, OD020026 and the NIDA-IRP.

\section{Author contributions}

B.D.R. and K.S. performed TIRF and electrophysiology experiments, and B.D.R., K.S. and E.C. performed confocal microscopy experiments, with guidance from H.K. M.-F.Z. and A.H.N. Biochemical experiments were performed by D.K. and B.F. under guidance from L.K.H. Analysis was performed by B.D.R. and D.K. The project was initiated by H.K., B.D.R. and J.S. Together, B.D.R., K.S., L.K.H. and H.K. designed experiments. B.D.R. and H.K. wrote the manuscript with significant input from L.K.H, D.K. and A.H.N.

\section{Additional information}

Supplementary Information accompanies this paper at http://www.nature.com/ naturecommunications

Competing financial interests: The authors declare no competing financial interests.

Reprints and permission information is available online at http://npg.nature.com/ reprintsandpermissions/

How to cite this article: Richardson, B. D. et al. Membrane potential shapes regulation of dopamine transporter trafficking at the plasma membrane. Nat. Commun. 7:10423 doi: $10.1038 /$ ncomms10423 (2016).

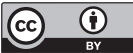

This work is licensed under a Creative Commons Attribution 4.0 International License. The images or other third party material in this article are included in the article's Creative Commons license, unless indicated otherwise in the credit line; if the material is not included under the Creative Commons license, users will need to obtain permission from the license holder to reproduce the material. To view a copy of this license, visit http://creativecommons.org/licenses/by/4.0/ 